\title{
Diet, nutrition and the prevention of dental diseases
}

\author{
Paula Moynihan ${ }^{1, *}$ and Poul Erik Petersen ${ }^{2}$ \\ 'WHO Collaborating Centre for Nutrition and Oral Health, School of Dental Sciences, University of Newcastle upon \\ Tyne, Newcastle upon Tyne, UK: ${ }^{2}$ WHO Collaborating Centre for Community Oral Health Programmes and \\ Research, University of Copenhagen, Copenhagen, Denmark
}

\begin{abstract}
Oral health is related to diet in many ways, for example, nutritional influences on craniofacial development, oral cancer and oral infectious diseases. Dental diseases impact considerably on self-esteem and quality of life and are expensive to treat. The objective of this paper is to review the evidence for an association between nutrition, diet and dental diseases and to present dietary recommendations for their prevention. Nutrition affects the teeth during development and malnutrition may exacerbate periodontal and oral infectious diseases. However, the most significant effect of nutrition on teeth is the local action of diet in the mouth on the development of dental caries and enamel erosion. Dental erosion is increasing and is associated with dietary acids, a major source of which is soft drinks.

Despite improved trends in levels of dental caries in developed countries, dental caries remains prevalent and is increasing in some developing countries undergoing nutrition transition. There is convincing evidence, collectively from human intervention studies, epidemiological studies, animal studies and experimental studies, for an association between the amount and frequency of free sugars intake and dental caries. Although other fermentable carbohydrates may not be totally blameless, epidemiological studies show that consumption of starchy staple foods and fresh fruit are associated with low levels of dental caries. Fluoride reduces caries risk but has not eliminated dental caries and many countries do not have adequate exposure to fluoride.

It is important that countries with a low intake of free sugars do not increase intake, as the available evidence shows that when free sugars consumption is $<15-20 \mathrm{~kg} / \mathrm{yr}$ ( $\sim 6-10 \%$ energy intake), dental caries is low. For countries with high consumption levels it is recommended that national health authorities and decision-makers formulate country-specific and community-specific goals for reducing the amount of free sugars aiming towards the recommended maximum of no more than $10 \%$ of energy intake. In addition, the frequency of consumption of foods containing free sugars should be limited to a maximum of 4 times per day. It is the responsibility of national authorities to ensure implementation of feasible fluoride programmes for their country.
\end{abstract}

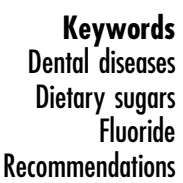

Dental diseases include dental caries, developmental defects of enamel, dental erosion and periodontal disease. The main cause of tooth loss is dental caries in which diet plays an important role. Diet also plays a significant aetiological role in dental erosion, the prevalence of which seems to be increasing, and dietary components may contribute to development of enamel defects (e.g. enamel hypoplasia, fluorosis). However, in modern societies, diet and nutrition play a relatively minor role in the aetiology of periodontal disease (gum disease), another cause of tooth loss in adults. This review will mainly focus on the major dental diseases, dental caries and dental erosion. Diseases of the oral mucosa, will not be reviewed in depth, as the paper focuses on dental disease. Oral cancer is covered in the background paper 'Diet and the prevention of cancer'.

\section{The burden of dental diseases}

Dental diseases are a costly burden to health care services. The treatment of dental caries is expensive for governments of both developed and developing countries and costs between 5 and 10\% of total health care expenditures in industrialised countries exceeding the cost of treating cardiovascular disease, cancer and osteoporosis ${ }^{1}$. In most developing low-income countries, the prevalence rate of dental caries is high and more than $90 \%$ of caries is untreated. The level of caries is higher for the primary 
dentition than the permanent dentition for children of several developing countries as shown recently for China ${ }^{2}$, Thailand $^{3}$, Madagascar ${ }^{4}$ and Niger ${ }^{5}$. The severity of disease in the permanent teeth is generally low and mostly limited to the occlusal and buccal/lingual surfaces. Available data ${ }^{6}$ show that the mean DMFT at age 12 years of low-income countries is 1.9 compared with 3.3 DMFT for middleincome countries and 2.1 DMFT for high-income countries. In low-income countries, the cost of traditional restorative treatment of dental disease is disproportionately expensive in light of the low public health priority and it would exceed the available resources for health care. The large financial benefits of preventing dental diseases should be emphasised to countries where current disease levels are low.

\section{The impact of dental diseases on quality of life}

Despite a low mortality rate associated with dental diseases, they have a considerable impact on self-esteem, eating ability, nutrition and health both in childhood and older age. Teeth are important in enabling consumption of a varied diet and in preparing the food for digestion. In modern society, the most important role of teeth is to enhance appearance; facial appearance is very important in determining an individual's integration into society. Teeth also play an important role in speech and communication. The second International Collaborative Study of Oral Health Systems (ICSII) ${ }^{7}$ revealed that in all countries covered by the survey substantial numbers of children and adults reported impaired social functioning due to oral disease, such as avoiding laughing or smiling due to poor perceived appearance of teeth. Throughout the world, children frequently reported apprehension about meeting others because of the appearance of their teeth or that others made jokes about their teeth. In addition, dental diseases cause considerable pain and anxiety ${ }^{8}$. These factors are likely to be exacerbated in less developed societies where pain control and treatment are not readily available. For example, in Thailand, half the children of age 12 claimed pain or discomfort from teeth within the past year $^{3}$ and $40 \%$ of children had tooth extraction at their last visit to the dentist. Similar patterns are observed in other countries such as China ${ }^{9}$, Jordan ${ }^{10}$ or Madagascar ${ }^{11}$.

Dental decay also results in tooth loss, which reduces the ability to eat a varied diet. It is, in particular, associated with a diet low in fruits, vegetables and non-starch polysaccharides (NSP), and with a low plasma vitamin C level ${ }^{12,13}$. NSP intakes of less than $10 \mathrm{~g} / \mathrm{d}$ and fruits and vegetable intakes of less than $160 \mathrm{~g} / \mathrm{d}$ have been reported in edentulous subjects ${ }^{13-15}$. Tooth loss may, therefore, impede the achievement of dietary goals related to the consumption of fruits, vegetables and NSP. Tooth loss has also been associated with loss of enjoyment of food and confidence to socialise ${ }^{13}$. It is, therefore, clear that dental diseases have a detrimental effect on quality of life both in childhood and older age.

\section{Dental caries}

The deciduous teeth erupt from 6 months and are lost by the early teens. The permanent dentition replaces the deciduous dentition from the age of 6 years and is complete by age 21 . Teeth are most susceptible to dental caries soon after they erupt; therefore, the peak ages for dental caries are $2-5$ years for the deciduous dentition and early adolescence for the permanent dentition. In developed countries, there is a trend for older adults now to retain their teeth for longer, however, if the gums recede with age the roots of the teeth become exposed, and, being relatively less mineralised than the tooth crowns, are susceptible to decay known as 'root caries"7.

Nutritional status affects the teeth during the preeruptive stage, however, this nutritional influence is much less important that the post-eruptive local effect of dietary practices on caries formation. Deficiencies of vitamin D, vitamin A and protein energy malnutrition (PEM) have been associated with enamel hypoplasia. PEM and vitamin A deficiency are also associated with salivary gland atrophy which subsequently reduces the mouth's defence against infection and its ability to buffer plaque acids. Navia ${ }^{16}$ states 'moderate malnutrition, particularly lack of protein and deficiencies of certain micronutrients such as vitamins, zinc and iron, can influence the amount and composition of saliva limiting the protective effects it has in the oral cavity'. However, in developing countries, in the absence of dietary sugars, undernutrition is not associated with dental caries. Undernutrition coupled with daily increased amount and/or frequency of sugars results in levels of caries greater than expected for the level of sugars intake.

Dental caries occurs due to demineralisation of enamel and dentine (the hard tissues of the teeth) by organic acids formed by bacteria in dental plaque through the anaerobic metabolism of sugars derived from the diet ${ }^{17}$. When sugars or other fermentable carbohydrates are ingested, the resulting fall in dental plaque $\mathrm{pH}$ caused by organic acids increases the solubility of calcium hydroxyapatite in the dental hard tissues and demineralisation occurs as calcium is lost from the tooth surface. The $\mathrm{pH}$ at which demineralisation occurs is often referred to as the critical $\mathrm{pH}$ and is approximately 5.5. Saliva is one of the mouth's natural defences against this process. Saliva promotes remineralisation, i.e. it is capable of depositing mineral in porous areas where demineralisation of enamel or dentine has occurred. Saliva is super-saturated with calcium and phosphate at $\mathrm{pH} 7$; this favours the deposition of calcium. If a demineralised lesion is formed it will be remineralised; although this is a slow process that competes with factors that cause demineralisation. If the $\mathrm{pH}$ in the mouth remains high enough for sufficient time then complete remineralisation of enamel may occur. However, if the acid challenge is too great, demineralisation dominates and the enamel becomes more porous until finally a carious lesion forms ${ }^{18}$. The rate of demineralisation is 
affected by the concentration of hydrogen and fluoride ions (i.e. $\mathrm{pH}$ at the tooth surface). Fluoride inhibits the demineralisation process and the frequency with which the plaque $\mathrm{pH}$ falls below the critical $\mathrm{pH}$ without subsequent remineralisation. So overall, caries occurs when demineralisation exceeds remineralisation. The way that fluoride promotes remineralisation will be discussed later.

The development of caries requires sugars and bacteria to occur but is influenced by the susceptibility of the tooth, the bacterial profile, quantity and quality of the saliva, and the time for which fermentable dietary carbohydrates are available for bacterial fermentation. Streptococcus mutans and Streptococcus sorbrinus are important bacteria in the development of dental caries. Both these bacteria readily produce organic acids from dietary sugars and like most aciduric bacteria can synthesise insoluble plaque matrix polymers (extracellular dextran) from dietary sugars-a factor that aids bacterial colonisation of the tooth surface. Growth of these streptococci requires the presence of fermentable monosaccharides. Mutans streptococcal invertase splits sucrose into glucose and fructose, which can be metabolised to produce mainly lactic but also other acids including acetic and formic acids. The resulting low $\mathrm{pH}$ alters the plaque ecology. A low $\mathrm{pH}$ in plaque is ideal for aciduric bacteria such as streptococci, lactobacilli and bifidobacteria as these are more competitive at low $\mathrm{pH}$ than bacteria not associated with dental caries.

\section{Dental erosion}

Dental erosion is the progressive irreversible loss of dental hard tissue that is chemically etched away from the tooth surface by extrinsic and/or intrinsic acids and/or chelation by a process that does not involve bacteria. Erosion is often associated with other forms of tooth wear such as abrasion and attrition (from over zealous oral hygiene and grinding of teeth, for example). Poor salivary flow or salivary deficiencies are thought to make some individuals more susceptible to acid challenges. Low salivary flow rate or inadequate buffering capacity are factors that exacerbates erosion ${ }^{19,20}$. Intrinsic acids are from vomiting and regurgitation. The extrinsic acids are from the diet, e.g. citric acid, phosphoric acid, ascorbic acid, malic acid, tartaric acid and carbonic acids found in fruits and fruit juices, soft drinks-both carbonated and still, some herbal teas, dry wines and vinegar-containing foods. The critical $\mathrm{pH}$ of enamel is $\sim 5.5$ and therefore any drink or food with a lower $\mathrm{pH}$ may cause erosion. Erosion reduces the size of the teeth and in severe cases leads to total tooth destruction $^{21}$. Extensive dental erosion requires expensive restorative treatment.

\section{Periodontal disease}

Periodontal disease is a chronic disease that may only become apparent in middle age. Apart from severe vitamin $\mathrm{C}$ deficiency, which results in scurvy-related periodontitis, there is little evidence for an association between diet and periodontal disease, although current interest is focusing on the potential preventive role of antioxidant nutrients. The main overriding factor in the aetiology of periodontal disease is the presence of plaque, and prevention measures focus on oral hygiene. There is some evidence to suggest that periodontal disease progresses more rapidly in undernourished populations and the important role of nutrition in maintaining an adequate host immune response may explain this observation ${ }^{22}$. Overgrowth of periodontopathic organisms and yeasts has been observed in malnourished African children ${ }^{23,24}$. A high sucrose intake is associated with increased plaque volume due to the production of extracellular glucans, and there is a strong association between plaque volume and gingivitis. Human intervention studies have shown higher plaque volumes and increased gingivitis with high sucrose diets compared with low sucrose diets ${ }^{25,26}$. However, Gaengler et $a l^{27}$ pointed out that the maximum reduction in sugar in the diet within the limits of practicability is not capable of preventing the development of gingivitis'. The role of dietary practices in the prevention of periodontal disease will not be discussed further.

\section{Nutrition and oral infectious diseases}

Malnutrition consistently impairs innate and adaptive defences of the host, including phagocytic function, cellmediated immunity, complement system, secretory antibody, and cytokine production and function. In PEM, there are marked changes in the oral microbial ecology resulting in a preponderance of pathogenic anaerobic organisms, increased propensity of bacteria to bind to oral mucosal cells, attenuation of acute phase protein response, and dysfunction of the cytokine system. Cellular depletion of antioxidant nutrients promotes immunosuppression, accelerated replication rate of ribonucleic acid viruses and increased disease progression.

Therefore, malnutrition can intensify the severity of oral infections and may lead to their evolution into lifethreatening diseases. The impact on oral health of malnutrition was recently reviewed by Enwonwu et al. ${ }^{28}$. Among the suspected causative factors are increased oral burden of free glucocorticoids and impaired host defence of saliva. No inflammatory oral lesions underscore the association between malnutrition and oral health as lucidly as acute necrotising gingivitis (ANG) and noma (cancrum oris). ANG is a craterlike lesion involving the interproximal gingival papillae and predominantly affects impoverished young children (3-10 years of age) who are generally immunocompromised by malnutrition and common tropical infections. If not promptly treated, ANG and other oral inflammatory lesions in malnourished children may evolve into noma (cancrum oris). This is a dehumanising orofacial gangrene that destroys the soft and hard tissues of the oral and paraoral structures. 


\section{Current epidemiological situation/trends in dental diseases}

\section{Trends in the prevalence of dental caries}

The extent of dental decay is measured using the dmft/DMFT (primary dentition/permanent dentition) index. This is a count of the number of teeth in a person's mouth that are decayed, filled or extracted. The $\mathrm{dmft} / \mathrm{DMFT}$ indices are widely used for indication of the prevalence of dental caries and the severity of dental caries experience in populations. The dental diseases-caries and periodontal disease-result in tooth loss and therefore the dental status of a population may also be assessed by looking at the proportion of the population who are edentulous (have no natural teeth).

The extent of epidemiological data varies widely between countries. For many countries there is very little information, and few countries have undertaken repeated cross-sectional data on representative samples of the population. Different countries may use different methods in epidemiological surveys of dental health and this may complicate between-country comparisons.

WHO established a Global Data Bank on Oral Health in 1969 and data continue to be added to this valuable source of dental health information. In 1982, WHO and FDI jointly set out global goals for oral health to be achieved by the turn of the century including that children aged 12 years on average should have a DMFT of below $3^{29}$.

The data in Table 1 show the trends in dental caries prevalence for both developed and developing countries for children aged 12 years. From these data two distinct trends are observed. First, the distinct fall in the prevalence of dental caries in developed countries, and second, the increase in the prevalence of the disease in some developing countries that have increased their daily ingestion of sugars and have not yet been introduced to the presence of adequate amounts of daily fluoride. Despite the marked decline in dental caries in developed countries over the past 30 years, dental caries remains unacceptably high in many developed countries and is a major public health problem. Countries with scores above 3 DMFT, which have failed to meet the WHO global goal for the year 2000, are listed in Table 2. In Europe, the Baltic States and Eastern Europe have high levels of caries. However, even in countries with low average DMFT scores (indicating low severity of the disease), dental caries still affects the majority of children. Of the industrialised nations the countries where less than half of 12-year-old children have decay experience are The Netherlands, Japan, the Scandinavian countries, the United Kingdom and the United States of America. There is some indication that the favourable trends in dental caries levels have come to a halt or that the gradual decrease in caries prevalence over the last half-century has stabilised ${ }^{30}$.

There are few data available on the dental health status of preschool children largely because many dental health surveys are conducted in schools for convenience. A review by $\mathrm{Holm}^{31}$ reported quite high levels of decay in this age group in many countries. In most of the developing countries and South-east Asia, children have a high prevalence of dental caries in the deciduous dentition. In Africa, the prevalence of dental caries in young children is increasing in some parts and is associated with an increase in sugars consumption, while it stays low in countries where a poor economy restricts sugars consumption ${ }^{31}$. Data on 5-year-old

Table 1 Trends in dental caries levels of 12-year-olds in industrialised and developing countries

\begin{tabular}{|c|c|c|c|c|c|c|}
\hline \multirow[b]{2}{*}{ Country } & \multicolumn{6}{|c|}{ Mean DMFT per person aged 12 years } \\
\hline & Year & DMFT & Year & DMFT & Year & DMFT \\
\hline \multicolumn{7}{|l|}{ Industrialised countries } \\
\hline Australia & 1956 & 9.3 & 1982 & 2.1 & 1998 & 0.8 \\
\hline Finland & 1975 & 7.5 & 1982 & 4.0 & 1997 & 1.1 \\
\hline Japan & 1975 & 5.9 & 1993 & 3.6 & 1999 & 2.4 \\
\hline Norway & 1940 & 12.0 & 1979 & 4.5 & 1999 & 1.5 \\
\hline Switzerland & $1961-63$ & 9.6 & 1980 & 1.7 & 1996 & 0.8 \\
\hline United Kingdom & 1983 & 3.1 & 1993 & 1.4 & $1996-97$ & 1.1 \\
\hline Romania & 1985 & 5.0 & 1991 & 4.3 & 1996 & 3.8 \\
\hline United States of America & 1946 & 7.6 & 1980 & 2.6 & 1998 & 1.4 \\
\hline \multicolumn{7}{|l|}{ Developing countries } \\
\hline Chile & 1960 & 2.8 & 1978 & 6.6 & 1996 & 4.1 \\
\hline French Polynesia & 1966 & 6.5 & 1986 & 3.2 & 1994 & 3.2 \\
\hline Islamic Republic of Iran & 1974 & 2.4 & 1976 & 4.9 & 1995 & 2.0 \\
\hline Jordan & 1962 & 0.2 & 1981 & 2.7 & 1995 & 3.3 \\
\hline Mexico & 1975 & 5.3 & 1991 & $2.5-5.1$ & 1997 & 2.5 \\
\hline Morocco & 1970 & 2.6 & 1980 & 4.5 & 1999 & 2.5 \\
\hline Philippines & 1967 & 1.4 & 1981 & 2.9 & 1998 & 4.6 \\
\hline Uganda & 1966 & 0.4 & 1987 & 0.5 & 1993 & 0.4 \\
\hline Zaire & 1971 & 0.1 & 1982 & 0.3 & 1987 & $0.4-1.1$ \\
\hline
\end{tabular}

Source: WHO Global Oral Health Data Bank ${ }^{6}$. 
Table 2 Countries for which data post 1995 are available that have not achieved the WHO goal for the year 2000 of DMFT $<3.0$ at the age of 12 years

\begin{tabular}{|c|c|c|}
\hline Region/country & DMFT & Year \\
\hline \multicolumn{3}{|l|}{ Europe } \\
\hline Bosnia and Herzegovina & 8.6 & 1998 \\
\hline Bulgaria & 4.2 & 1998 \\
\hline Croatia & 3.5 & 1999 \\
\hline Czech Republic & 3.4 & 1998 \\
\hline Hungary & 3.8 & 1996 \\
\hline Latvia & 4.2 & 1998 \\
\hline $\begin{array}{l}\text { The Former Yugoslav Republic } \\
\text { of Macedonia }\end{array}$ & 3.6 & 1996 \\
\hline Poland & 4.1 & 1999 \\
\hline Russian Federation & 3.7 & 1995 \\
\hline Slovakia & 4.3 & 1999 \\
\hline \multicolumn{3}{|l|}{ Eastern Mediterranean } \\
\hline Jordan & 3.3 & 1995 \\
\hline \multicolumn{3}{|l|}{ The Americas } \\
\hline Bolivia & 4.7 & 1995 \\
\hline Brazil & 3.1 & 1996 \\
\hline Chile & 4.1 & 1996 \\
\hline Costa Rica & 4.8 & 1996 \\
\hline Dominican Republic & 4.4 & 1997 \\
\hline Honduras & 3.7 & 1997 \\
\hline Panama & 3.6 & 1997 \\
\hline \multicolumn{3}{|l|}{ Western Pacific } \\
\hline Republic of Korea & 3.1 & 1995 \\
\hline Philippines & 4.6 & 1998 \\
\hline Tokelau & 4.8 & 1999 \\
\hline
\end{tabular}

Source: WHO Global Oral Health Data Bank ${ }^{6}$.

children from the $\mathrm{UK}^{32}$, The Netherlands ${ }^{33}$ and Denmark ${ }^{34}$ suggest that the trend towards reduced prevalence of dental decay has halted. In a review of the prevalence and severity of dental caries in the deciduous dentition of children aged 5-7 years in Europe ${ }^{35}$, average dmft values of below 2.0 were found for Denmark, England, Finland, Italy, The Netherlands and Norway. Higher levels of decay $(\mathrm{dmft})$ were reported recently for Belarus $(4.7)^{36}$, Hungary $(4.5)^{37}$, Romania $(4.3)^{38}$ and Russia $(4.7)^{39}$.

\section{Dental caries in adults}

Being caries-free at age 12 does not imply being caries-free for life, as dental caries affects adults as well as children and the severity of the disease increases with age ${ }^{40,41}$. Holst and Schuller showed, from a cohort study of Norwegians, that despite a mean DMFT of 3.0 at age 13 years this increased to 8 at age 23 and 15 at age $33^{41}$. In the Republic of Ireland, the mean DMFT of 20 and 24-yearolds was 9.5 and 11.3, respectively. Even in fluoridated areas of Ireland the mean DMFT of 35-44-year-olds was 18.9 indicating that fluoridation has not eradicated the disease of dental caries ${ }^{42}$. The DMFT of 16-24-year-olds in the UK was 10.8 and increased to 16.0 at $25-34$ years and to 19.0 at $35-44$ years $^{8}$. The mean DMFT of adults in European Union countries after 1988 varied between 13.4 and 20.8 at $35-44$ years $^{43}$. In the US, improvements have been noted over the past 25-30 years with regard to dental caries. Among most age groups, the average number of teeth per person affected by dental caries has decreased while the proportion of the population that is cariesfree has increased ${ }^{44}$. The WHO Oral Health Guidelines state that at age 35-44 years a DMFT of 14 or above is considered high. In most developing countries, the level of caries in adults of this age group is lower, e.g. in Niger $(\mathrm{DMFT}=5.7)^{5}$ or in China $(\mathrm{DMFT}=2.1)^{2}$.

There are few data available on the prevalence and severity of root caries in older adults. The UK NDNS of people aged 65 years and over reported that $80 \%$ of dentate persons over 65 years had decay to the root or root restorations $^{13}$. The 1998 Adult Dental Health Survey showed that overall $66 \%$ of dentate adults have at least one tooth with a root that was either exposed, worn, filled or decayed with an average of 6.4 teeth involved. Nearly onequarter of adults had 12 or more teeth in this condition and in the $65+$ age group $43 \%$ had root fillings ${ }^{8}$. A study of adults conducted in Scandinavia showed that the prevalence of root caries was $27-33 \%$ in the older adults but the mean number of teeth affected was low $(0.9)^{40}$. Finally, the Second National Survey of Oral Health in China showed that at the age of 65-74 years the mean number of teeth affected by root caries was $0.5^{2}$. With an ageing population and greater retention of teeth, root caries is likely to grow as a public health issue in the future. Few studies have investigated the relationship between root caries and either diet or nutrition, however, the UK National Diet and Nutrition Survey of people aged 65 years and over found a significant relationship between frequency of intake of non-milk extrinsic (NME) sugars (free sugars) and root caries.

\section{Summary of trends in dental caries}

The prevalence and severity of dental caries in industrialised countries has decreased in the last three decades but improvements have now halted in younger age groups. In developing countries where fluoride is not available and populations have more opportunity to consume free sugars and other fermentable carbohydrates, the prevalence of decay is increasing. In South-east Asia and in some parts of Africa, studies indicate that decay in the primary dentition is increasing. Within most countries, geographical and social factors influence the occurrence of dental caries and, despite improvements, caries continues to affect the majority of children, some severely. Dental caries is the most common dental disease in children and contributes to tooth loss in adults.

\section{Trends in patterns of tooth loss}

Retention of teeth into later life is of utmost importance in enabling consumption of a varied nutritious diet. Dentures are not a satisfactory substitute for natural teeth and limit the ability to consume a healthy diet adequate in fruits, vegetables and $\mathrm{NSP}^{13}$. In terms of tooth loss statistics, few countries have good repeated cross-sectional data on 
representative samples of the population. The ICSII study ${ }^{7}$ indicated a reduction over-time for the number of edentulous persons for several industrialised countries, however, tooth loss and use of dentures remains more prevalent among the socio-economically disadvantaged people. This has also been shown for adults in Scandinavia ${ }^{45}$. The UK has national surveys of the dental health of adults that were undertaken in 1968, 1978, 1988 and 1998. The number of adults (over 18 years) who are edentulous has fallen in the UK from $37 \%$ in 1968 to $13 \%$ in $1998^{8}$. However, in the $65+$ age group almost $50 \%$ are still edentulous.

In industrialised countries, there has been a fall in the proportion of the adult population that are edentulous. This is a welcome trend but there is still a large proportion of older adults who are edentulous or partially dentate. With the increase in the ageing population, tooth loss will continue to affect a sizeable number of persons in the foreseeable future. Table 3 summarises the available information on the prevalence of edentulousness for different countries.

Table 3 Prevalence of edentulousness among elderly throughout the world

\begin{tabular}{|c|c|c|}
\hline Country/region & $\%$ Edentulous & Age group \\
\hline $\begin{array}{l}\text { The Americas } \\
\text { USA } \\
\text { Canada }\end{array}$ & $\begin{array}{l}26.0 \\
58.0\end{array}$ & $\begin{array}{c}65-69 \\
65+\end{array}$ \\
\hline $\begin{array}{l}\text { Africa } \\
\text { Gambia } \\
\text { Madagascar }\end{array}$ & $\begin{array}{r}6 \\
25\end{array}$ & $\begin{array}{c}65+ \\
65-74\end{array}$ \\
\hline $\begin{array}{l}\text { Eastern Mediterranean } \\
\text { Egypt } \\
\text { Lebanon } \\
\text { Saudi Arabia }\end{array}$ & $\begin{array}{c}7 \\
20 \\
31-46\end{array}$ & $\begin{array}{c}65+ \\
64-75 \\
65+\end{array}$ \\
\hline $\begin{array}{l}\text { Western Pacific } \\
\text { Cambodia } \\
\text { China } \\
\text { Malaysia } \\
\text { Singapore }\end{array}$ & $\begin{array}{l}13.0 \\
11 \\
57 \\
21\end{array}$ & $\begin{array}{c}65-74 \\
65-74 \\
65+ \\
65+\end{array}$ \\
\hline $\begin{array}{l}\text { South-East Asia } \\
\text { India } \\
\text { Indonesia } \\
\text { Sri Lanka } \\
\text { Thailand }\end{array}$ & $\begin{array}{l}19 \\
24 \\
37 \\
16.3\end{array}$ & $\begin{array}{c}65-74 \\
65+ \\
65-74 \\
65+\end{array}$ \\
\hline $\begin{array}{l}\text { Europe } \\
\text { Albania } \\
\text { Austria } \\
\text { Bosnia and Herzegovina } \\
\text { Bulgaria } \\
\text { Denmark } \\
\text { Finland } \\
\text { Hungary } \\
\text { Iceland } \\
\text { Italy } \\
\text { Lithuania } \\
\text { Poland } \\
\text { Romania } \\
\text { Slovakia } \\
\text { Slovenia } \\
\text { United Kingdom }\end{array}$ & $\begin{array}{l}69 \\
15 \\
78 \\
53 \\
27 \\
41 \\
27 \\
15 \\
19 \\
14 \\
25 \\
26 \\
44 \\
16 \\
46\end{array}$ & $\begin{array}{c}65+ \\
65-74 \\
65+ \\
65+ \\
65-74 \\
65+ \\
65-74 \\
65-74 \\
65-74 \\
65-74 \\
65-74 \\
65-74 \\
65-74 \\
65+ \\
65+\end{array}$ \\
\hline
\end{tabular}

Source: WHO Global Oral Health Data Bank ${ }^{6}$.

\section{Trends in dental erosion}

Dental erosion is a relatively newly recognised dental problem and which has been related to $\operatorname{diet}^{46,47,48}$. Although there is anecdotal evidence that the prevalence is increasing in industrialised countries, longitudinal data on epidemiological trends do not yet exist. Cate and Imfeld summarised information on prevalence of dental erosion and stated that, between 8 and $13 \%$ of adults had at least one erosive lesion on the labial incisors that involved the dentine ${ }^{49}$. A further 30-43\% had between 3.1 and 3.9 teeth affected by occlusal lesions involving the dentine. Lingual lesions were found in only $2 \%$ of subjects. There are insufficient data available to comment on worldwide trends; however, the UK has data on the prevalence of dental erosion for representative samples of population age groups that shows erosion to increase with age. Of children aged 1.5-2.5 years, 3\% had severe erosion that involved the pulp of the teeth but this figure increased to $13 \%$ in 3.5-4.5-year-olds ${ }^{50}$. The Child Dental Health Survey showed that $52 \%$ of 5 and 6 -year-olds had erosion to deciduous incisors and in half of these cases it was severe (involved the pulp). Erosion also affects the permanent dentition with $28 \%$ of $11-14$-year-olds having erosion and $2 \%$ having severe erosion ${ }^{51}$. The National Diet and Nutrition Survey (NDNS) of young people aged 4-18 years showed that half the study population had evidence of erosion in the upper incisors or in the first molars of either the deciduous or permanent dentition. In the 4-6 years age group $65 \%$ had erosion and $62 \%$ of $15-18$-yearolds had erosion of the permanent dentition ${ }^{52}$. The trend towards increased consumption of acidic beverages over recent decades is often suggested as a dietary factor in dental erosion in industrialised societies.

\section{Review of the current thinking: the scientific evidence linking diet and dental diseases}

There is a wealth of evidence to show the role of dietary sugars in the aetiology of dental caries. The evidence comes from many different types of investigation including human studies (both observational and intervention), human plaque $\mathrm{pH}$ studies (in which the $\mathrm{pH}$ of plaque is monitored in situ following ingestion of a test substance), enamel slab experiments (in which slabs of bovine enamel are fitted in a removable oral appliance and worn during periods of consumption of experimental diets and subsequently the level of demineralisation is measured), animal studies and incubation studies of oral bacteria and dietary substrates in vitro. Collectively, information from all the different types of studies provides an overall picture of the cariogenic potential of different dietary carbohydrates. The strength of the evidence linking sugars in the aetiology of dental caries comes from the multiplicity of the studies rather than the power of any one study alone ${ }^{17}$. It is worth noting that some of 
the earlier epidemiological studies were done in communities that did not have the benefit of exposure to fluoride.

\section{Dietary sugars and dental caries}

The evidence shows that sugars are undoubtedly the most important dietary factor-and the factor studied most often-in the development of dental caries. In this paper, the term 'sugars' refers to all mono and disaccharides while the term 'sugar' only refers to sucrose, the term 'free sugars' refers to all mono and disaccharides added to foods by manufacturer, cook or consumer, plus sugars naturally present in honey, fruit juices and syrups and the term 'fermentable carbohydrate' refers to free sugars, glucose polymers, fermentable oligosaccharides and highly refined starches.

\section{Worldwide epidemiological observational studies}

Sugar intake and levels of dental caries can be compared at country level. Sreebny ${ }^{53}$ correlated the dental caries experience of primary dentition (dmft) of 5 and 6-yearolds with sugar supplies data of 23 countries, and the dental caries experience (DMFT) of 12-year-olds to sugar supplies data of 47 countries. For both age groups, significant correlations were observed: +0.31 for deciduous dentition and +0.7 for permanent dentitionmeaning that $52 \%$ of the variation in caries levels could be explained by the per capita availability of sugar. From these data it was calculated that for every $25 \mathrm{~g}$ of sugar per day one tooth per child would become decayed, missing or filled ${ }^{54}$. In countries with an intake of sugar below $18 \mathrm{~kg} /$ person $/$ yr (equivalent to $\sim 50 \mathrm{~g} /$ person $/ \mathrm{d})(n=21)$ experience of caries was consistently below DMFT 3 (the WHO goal for 2000). The countries with sugar supplies in excess of $44 \mathrm{~kg} /$ person/yr $(120 \mathrm{~g} /$ person/d) had significantly higher levels of caries.

The previous data refer to populations of children who were not exposed to the benefits of fluoride. This point is well demonstrated by a later analysis by Woodward and Walker who did not find such a strong association between per capita sugar availability and mean DMFT of 12 -year-olds in developed $(n=29)$ and developing $(n=61)$ countries $^{55}$. In this analysis where one can presume that fluoride was present in the community, no association was found between sugar availability and caries levels in developed countries. However, Nadanovsky ${ }^{56}$ pointed out that the reason for an absence of relationship between sugar supply data and mean DMFT in developed countries was because with such very high availability of sugar in these countries, changing the level of sugar intake by a few $\mathrm{kg} / \mathrm{yr}$ does not influence the caries challenge. Woodward and Walker ${ }^{55}$ found that sugar availability accounted for $28 \%$ of the variation in levels of dental caries. It is worth noting that $28 \%$ is a substantial amount considering the crudeness of the analysis which relates to different examiners and accuracy of sugar supply data as regards actual consumption by 12 -year-olds; the fact that dental data are not necessarily based on representative samples, and the level of confounding factors (fluoride exposure and frequency of sugar consumption). The data from the analysis of Woodward and Walker show that 23 of the 26 countries with sugars availability below $50 \mathrm{~g} / \mathrm{d}$ had mean DMFT for 12-year-olds of below 3, whereas only half of the countries with sugar availability above this level had achieved DMFT $<3$. Over $78 \%$ of countries that had a low-sugar availability $(<10 \mathrm{~kg} /$ person/yr) had a mean DMFT at age 12 of $<2.0$.

Ruxton et al. ${ }^{57}$ used the ecological data from the studies of Sreebny and Woodward and Walker to study the relationship between changes in dental caries and changes in sugar intake in 67 countries between 1982 and 1994 by drawing up a simple scatter plot. This scatter plot showed that in 18 countries, where sugar supply declined, DMFT decreased. In 18 countries where caries level increased, there were increases in sugar supplies. In some countries, this relationship was not demonstrated; in 25 countries where caries had decreased sugars supply had increased and in 3 countries sugars declined and caries increased. Thus, overall, this crude analysis, that did not control for confounding factors such as frequency of intake and use of fluoride, showed that data from the majority of countries did support the association between sugar intake and dental caries. Furthermore, there were 17 countries with DMFT $<1$ that had sugar intakes of $<10 \mathrm{~g} /$ person $/$ d.

The weaker association between per capita sugar availability and levels of caries in industrialised countries may partly be accounted for by the fact that many sugars other than sucrose are contributing to total sugars intake. For example, in the USA there is a high use of high fructose corn syrup (similar to invert sugar) and in other industrialised countries the use of glucose syrups, fruit juice concentrates and glucose polymers is becoming widespread. Additionally, the extreme differences in daily use of fluoride dentifrice and availability of adequate amounts of fluoride in water supplies within countries, confounds the data.

\section{Dental caries patterns following changes in availability of dietary sugars}

Populations that had reduced sugar availability during the Second World War years showed a reduction in dental caries which subsequently increased when the restriction was lifted ${ }^{58-60}$. Takeuchi ${ }^{59}$ found that annual caries increment in the first molars between 1941 and 1958 mirrored annual sugar consumption. Marthaler ${ }^{60}$ analysed data from Switzerland and reanalysed wartime data from Norway and New Zealand to look at annual caries increments rather than absolute whole mouth caries experience and likewise found that caries increments mirrored sugar consumption. These analyses reported on amount of sugar consumed only and did not investigate the effect of frequency of sugar consumption on caries. It is not known if war time dietary restrictions resulted in a 
reduced frequency of consumption or whether meal patterns were retained but smaller amounts consumed.

Although these data are from before widespread use of fluoride dentifrice, Weaver ${ }^{61}$ observed a reduction in dental caries between 1943 and 1949 in areas of North England with both high and low water fluoride concentrations. More recently, Miyazaki and Morimoto ${ }^{62}$ reported a significant correlation $(r=+0.91)$ between sugar availability in Japan and DMFT at age 12 between 1957 and 1987. It should be noted that, during the Second World War, a reduction in intake of sugar was not an isolated dietary change and that intake of other carbohydrates, e.g. refined flour, was also restricted in some countries. The evidence concerning intake of starch and dental caries will be considered in Section 3.2.

Evidence for an association between dental caries and the intake of dietary sugars comes from epidemiological observational studies of dental caries levels in populations before and after an increase in sugar consumption. Isolated communities with a traditional way of life and a consistently low-sugar intake have very low dental caries levels. As economic levels in such societies rise, the amount of sugar and other fermentable carbohydrates in the diet increases as they shift towards habits and diets associated with modern living. Examples of this trend include populations in the Inuit in Alaska, USA ${ }^{63}$ as well as populations in Ethiopia ${ }^{64}$, Ghana ${ }^{65}$, Nigeria ${ }^{66,67}$, Sudan ${ }^{64}$ and on the Island of Tristan da Cunha, St Helena ${ }^{68}$.

There is evidence to show that many groups of people with habitually high consumption of sugars also have levels of caries higher than the population average, for example, children with chronic diseases requiring longterm sugar-containing medicines ${ }^{69}$. Environmental exposure to high sugars has also been studied: Anaise $\mathrm{f}^{70}$ found that confectionery industry workers had $71 \%$ higher dental caries experience than factory workers from other industries. Katayama ${ }^{71}$ also found higher caries in confectionery workers (DMFT 17.2) compared with workers in other industries (DMFT 11.4). These observations were made in an era prior to widespread use of fluoride; however, relatively more recently Petersen ${ }^{72}$ found that Danish chocolate factory workers had significantly higher dental caries experience and higher tooth loss than ship-yard workers, after controlling for confounding factors. This was then confirmed in another study of sweet biscuit factory workers in Finland ${ }^{73}$.

Low dental caries experience has been reported in groups of people who have a habitually low consumption of dietary sugars, for example, children of dentists ${ }^{74}$, children in institutions with strict dietary regimens ${ }^{75,76}$ and children with hereditary fructose intolerance (HFI $)^{77}$. Despite reports by parent dentists of restricted intake of sugars by their children, the low dental caries experience of these children cannot be assumed to be due to low sugars intake as other preventive care is likely to be greater in these children.
Children living in the Hopewood House children's home in New South Wales received annual dental surveys between 1947 and 1962 and followed a strict lactovegetarian diet that was low in sugars and refined flour. Their oral hygiene was virtually absent and fluoride exposure was low. Dental caries levels were much lower than children of the same age and socioeconomic background attending state schools in New South Wales. Forty-six percent of 12year-olds in Hopewood House were caries-free compared with $1 \%$ of the children from state schools. However, after 12 years of age when the children's association with the home ended the rate of caries increased to levels observed in children from the state schools ${ }^{75}$.

A weakness of the data from observations of populations is that changes in intake of sugars are often associated with changes in the intake of refined flour, making it impossible to attribute changes in dental caries solely to changes in the intake of sugars. A good exception to this is the data from studies of children with HFI. HFI is a congenital deficiency of fructose-1-phosphate aldolase. Consumption of fructose results in nausea and hypoglycaemia; hence, all foods containing fructose and sucrose are excluded from the diet. People with HFI, therefore, have a low intake of sugars but, as glucose is tolerated do not have a restriction on intake of starch. Studies have shown that subjects with HFI have a low intake of sugars and a higher than average intake of starch yet a low caries experience $^{77}$.

\section{Human intervention studies}

Human intervention studies where intake of sugars has been altered and caries development monitored are rare, partly due to the problems inherent in trying to prescribe diets for the long period of time necessary to measure changes in caries development. Those that have been reported are now decades old and were conducted in the prefluoride era on highly selected groups of people before the strong link between sugars intake and dental caries levels was established. Such studies would not be possible to repeat today because of ethical constraints.

The Vipeholm study was conducted shortly after the Second World War in an adult mental institution in Sweden between 1945 and $1953^{78}$. The study investigated the effects of consuming sugary foods of varying stickiness (i.e. different oral retention times) and at different times throughout the day on the development of caries by measuring caries increment in subjects that consumed (1) refined sugars with a slight tendency to be retained in the mouth at meal times only (e.g. sucrose solution, chocolate), (2) refined sugars with a strong tendency to be retained in the mouth at meal times only (e.g. sweetened bread), (3) refined sugars with a strong tendency to be retained in the mouth, in-between meals (e.g. toffee). The dietary regimes were given in two periods. The first carbohydrate period was between 1947 and 1949 and the second carbohydrate period (in which 
the regimens were changed slightly) ran between 1949 and 1951. It was found that sugars, even when consumed in large amounts, had little effect on caries increment if ingested up to a maximum of four times a day at mealtimes only. However, increased frequency of consumption of sugar in-between meals was associated with a marked increase in dental caries. It was also found that the increase in dental caries activity disappears on withdrawal of sugars. The study noted that dental caries experience showed wide individual variation. The study obviously demonstrates an effect of frequency of intake which will be discussed in more detail later. The significance of mealtime consumption of sugars is also that salivary flow rate is greater at mealtimes due to stimulation by other meal components and therefore plaque acids may be more rapidly neutralised.

The study had a complicated design and subjects were not randomly assigned to groups (as groups were determined by wards, to separate dietary regimens). The oral hygiene status or practices were uncertain or difficult to assess from the report. The fluoride concentration in the drinking-water was $0.4 \mathrm{ppm}$ (low) and the study was carried out before use of fluoride in dentifrices. Despite the complicated nature of the study the conclusions are valid yet apply to the prefluoride era.

A second important intervention study was the Turku study that was a controlled intervention study carried out in Finland in the $1970 \mathrm{~s}^{26}$. This was a study to evaluate the effect of almost total substitution of sucrose in a normal diet with either fructose or xylitol on caries development, but evidence from the control group can be used as indirect evidence for the impact of sugar consumption on the development of caries. Three groups of subjects ( $n=125$ in total) aged $12-53$ years, with $65 \%$ being in their twenties, consumed a diet sweetened with either sucrose, fructose or xylitol for a period of 25 months. Dental caries increment was monitored blind at 6-month intervals by one person throughout the study and both carious cavities and precavitation lesions were recorded. Foods were specially manufactured for the fructose and xylitol groups. Subjects were asked to avoid sweet fruits such as dried fruits, as sugars in these foods could not be substituted. The xylitol group consumed xylitol-containing foods significantly less frequently than the sucrose or fructose groups consumed their sweetened foods and the overall intake of xylitol in the xylitol group was lower than that of sucrose or fructose in the other groups. An 85\% reduction in dental caries was observed in the xylitol group who had removed sugar from their diet.

Table 4 Findings of the Turku Study ${ }^{26}$

\begin{tabular}{lcc}
\hline Group & DMFS (inc. precavitation) & DMFS (cavities only) \\
\hline Sucrose & 7.2 & 3.33 \\
Fructose & 3.8 & 3.57 \\
Xylitol & 0 & 1.47 \\
\hline
\end{tabular}

The findings are summarised in Table 4. Overall, the conclusions of the Turku Study are that substitution of sucrose in the Finnish diet (a high sugar diet) with xylitol resulted in a markedly lower dental caries increment for both carious cavities and precavitation lesions.

\section{Cross-sectional comparisons of diet and dental caries levels in populations}

When considering the findings of cross-sectional surveys it is important to consider that dental caries develops over time and therefore simultaneous measurements of disease levels and diet may not give a true reflection of the role of diet in the development of the disease. It is the diet and other factors several years earlier that may be responsible for current caries levels. Cross-sectional studies should, therefore, be interpreted with caution. This phenomenon is less of a problem in young children, whose diet may not have changed significantly since the eruption of the deciduous dentition.

Numerous cross-sectional epidemiological studies have compared sugars intake with dental caries levels in many countries of the world. Those before the early 1990s have been summarised by Rugg-Gunn ${ }^{79}$. All studies varied widely in methodology and means of reporting the findings making drawing of overall conclusions complicated. Nine out of 21 studies that compared weight of sugars consumed to caries increment found significant associations and the other $12 \mathrm{did}$ not. Twenty-three out of the 37 studies that investigated the association between frequency of sugars consumption and caries levels found significant relationships and 14 failed to find an association.

In addition to diet, some cross-sectional studies have also considered tooth brushing habits and exposure to fluoride. For example, Granath et al. ${ }^{80}$ compared the level of dental caries in over 500 4-year-old Swedish children to sugars consumption, fluoride supplementation and oral hygiene practices. Intake of sugars was the most important factor associated with dental caries, and differences in dental caries experience of children with the highest and lowest in-between meal sugars intake could not be explained by difference in use of fluoride or oral hygiene practices. When the effects of oral hygiene and fluoride were kept constant the children with a low-sugars intake in-between meals had 86\% less buccal and lingual caries and 68\% less approximal caries than children with high intakes of sugars in-between meals. In a study of over 2000 Finnish children aged between 7 and 16 years, Hausen et $a l^{81}$ showed that intake of sugars, water fluoridation level and tooth brushing frequency were all important determinants of dental caries experience although sugars exposure was the least important of these factors. Kleemola-Kujala and Rasenen ${ }^{82}$, in a study of three different age groups of Finnish children (5, 9 and 13 years), found that poor oral hygiene and high sugars intake were both related to dental caries though the former was 
the stronger relationship. Similar findings were obtained by Schroder and Granath $^{83}$ in a study of 3-year-old Swedish children. Stecksen-Blinks et $a l .{ }^{84}$ conducted a study that investigated relationships between oral hygiene habits and dental caries in Swedish children in three age groups (4, 8 and 13 years) living in three different areas in Sweden. Children from the south had more caries than children from the north in both the deciduous and permanent dentition. Differences in the levels of caries were explained by differences in oral hygiene practice and the age at which dental care commenced. There was little difference in the frequency of sugars intake between the different regions. A large cross-sectional study of 2514 Americans aged 9-29 years conducted between 1968 and 1970 found that the dental caries experience of adolescents eating the highest amounts of sugars (upper 15\% of the sample) was twice that of those eating the lowest amounts (lower $15 \%$ of the sample) ${ }^{85}$.

The UK National Diet and Nutrition Survey of people aged 65 years and older studied the relationship between levels of root caries and dietary habits and found a significant association between frequency of intake of NME sugars (free sugars) and root caries. However, no relationship between the amount of NME sugars consumed and levels of root caries was found ${ }^{13}$.

In the NDNS of young people aged 4-18 years, no overall relationship between amount of NME sugars consumed and levels of dental caries was observed. When children were divided into high, medium, or low bands of NME sugars consumption, no significant relationship was found between caries experience and band of NME sugars intake. However, in the 15-18-year-old age group, the upper band of intake of NME sugars was more likely to have decay than those in the lower band (70\% compared with $52 \%)^{52}$

Marques and Messer $^{86}$ failed to show an association between sugars intake and dental caries in the primary dentition. However, Persson et al. ${ }^{87}$ found that the consumption of high sucrose foods at age 12 months was positively related to the level of dental caries at age 3 years and Stecksen-Blinks and $\operatorname{Holm}^{88}$ showed that snacking frequency was positively associated with dental caries in the deciduous dentition of 4-year-old children in Sweden. In a study of Danish 6-year-old children, Petersen ${ }^{45}$ observed that high frequency of consumption of sweets and sugary drinks implied significantly higher amount and risk (Odds Ratio) of dental caries. This was found after control of confounders related to oral hygiene practices and socio-economic status. Furthermore, a recent UK survey of children aged 1.5-4.5 years showed that when social factors were controlled for, an association was found between frequency of consumption of confectionery and soft drinks, high intake of confectionery and soft drinks and dental caries ${ }^{50}$.

Some cross-sectional surveys on dietary habits and dental caries have been carried out on children of developing countries. For example, in Madagascar significantly higher dental caries experience index $(\mathrm{dmfs}+$ DMFS) was demonstrated for schoolchildren with frequent consumption of sweets, cakes and sugary drinks as compared to children with low scores of sugars consumption $^{11}$. Such an association was also indicated by recent studies conducted in Saudi Arabia ${ }^{89}$, Thailand ${ }^{3}$ and China $^{90}$. In these studies, confounder control was performed by application of multivariate regression analysis.

\section{Longitudinal studies of diet and caries incidence}

When investigating the association between diet and the development of dental caries it is more appropriate to use a longitudinal design in which sugars consumption habits over time are related to changes in dental caries experience. This type of study is relatively more costly and time consuming and in comparison to the number of cross-sectional studies in the literature, this type of study is relatively rare.

A number of studies have investigated the association between consumption of sugars-rich foods and caries development. Sundin ${ }^{91}$ monitored caries development in a group of Swedish children from repeated cross-sectional data and found a strong correlation between caries increment and the consumption of sweets. The relationship was strongest for those with poor $(+0.51)$ compared with good oral hygiene $(+0.11)$. Different fluoride exposure should also be considered in this respect. A further longitudinal study by Lachapelle-Harvey and Sevigny $^{92}$ compared the diets of 11 -year-old Canadian children with caries development over a 20 -month period. The dietary practices that were associated with caries increment in this rather short time were: chocolate or sugared chewing gum consumption in-between meals and consumption of iced cakes at meal times. In a more recent study (i.e. in the era of exposure to fluoride), Grindefjord et al. ${ }^{93}$ observed caries levels in a cohort of young children between the ages of 1 and 3.5 years. A significant relationship between the markers of frequent consumption of sugary items and sugars-containing beverages and caries increment was found.

Some studies have investigated the relationship between total sugars intake and caries development. Stecksen-Blicks and Gustafsson ${ }^{94}$ measured caries increment over 1 year in 8 and 13-year-old children and related it to diet at one time point. Despite the short period of observation, a significant relationship between caries development and intake of sugars was found for both the primary and permanent dentition. In a comprehensive study of dental caries increment and diet of over 400 English adolescents (aged 11-12 years) ${ }^{95}$ a small but significant relationship was found between intake of total sugars and caries increment over 2 years $(+0.2)$.

The Michigan Study was carried out in the USA between 1982 and 1985. It studied the relationship between sugars 
intake and dental caries increment over 3 years in children initially aged $10-15$ years ${ }^{96}$. This study also found weak relationships between the amount of dietary sugars and dental caries increment. Children who consumed a higher proportion of their total dietary energy as sugars had a higher caries increment for approximal caries, though there was no significant association between sugars intake and pit and fissure caries. The frequency of intake of sugars or sugar-containing foods (with $>15 \%$ sugars) was not related to caries increment, but the amount of sugars eaten in-between meals was related to approximal caries. When the children were divided into those who had a high compared with a low caries increment, a tendency towards more frequent snacking was seen in the high caries children. However, intake of sugars was generally high for all subjects in this study with only 20 out of 499 children consuming less than $75 \mathrm{~g} / \mathrm{d}$, and the average intake of the lowest quartile of consumption being $109 \mathrm{~g} / \mathrm{d}$ or $23.4 \%$ of energy intake. Burt and Szpunar ${ }^{97}$ recognised that, in the Michigan Study, the reason for the low relative risk of caries development in the high sugars consumers was that small variances were found both for caries increment and intake of sugars.

A review by Marthaler ${ }^{54}$ addressed whether the relationship between dietary sugars and caries activity is vanishing in westernised countries with high sugars availability and extensive use of fluoride dentifrices. It was concluded that data from longitudinal studies in modern societies that make use of prevention still show a relationship between sugars consumption and caries activity. Marthaler pointed out that many older studies failed to show a relationship between sugars intake and development of dental caries because many of these were of poor methodological design, used unsuitable methods of dietary analysis and were of insufficient power ${ }^{54}$. Additionally, the influence of frequency of consumption was generally ignored. Correlations between individuals' sugars consumption and dental caries increments may be weak due to the limited range of sugars intake in the study population, i.e. variation in sugars intake within populations is too low to show an effect on caries occurrence. If all people within a population are exposed to the disease risk factor the relationship between the risk factor and the disease will not be apparent ${ }^{98}$. There is more betweencountry variation in intake of sugars which explains the stronger association between sugar availability and dental caries levels found from analysis of worldwide data $(r=+0.7)^{53}$.

\section{Frequency of sugars consumption and the amount consumed}

The importance of frequency versus the total amount of sugars is difficult to evaluate as the two variables are hard to distinguish from each other. An increase of either parameter often automatically gives an increase in the other and likewise a reduction in frequency in intake of sugars in the diet should result in a reduction in the total sugars consumed.

Data from animal studies have indicated the importance of frequency of sugars intake in the development of dental caries. König ${ }^{99}$ showed that dental caries experience increases with increasing frequency of intake of sugars even when the absolute intake of sugars eaten by all groups of rats was the same. Firestone ${ }^{100}$ showed that less caries developed as the interval between feeds was increased.

Some human studies show that the frequency of sugars intake is an important aetiological factor for caries development ${ }^{53,101}$. The primary evidence for the belief that the prevalence of dental caries is directly related to the frequency with which sugar is eaten comes from the Vipeholm study ${ }^{78}$. This study showed caries development was low when sugars were consumed up to four times a day at mealtimes. Holbrook et al. ${ }^{102}$, in a study of 5 -yearold children in Iceland, also found a threshold effect for the frequency of sugars consumption on caries development of four times a day. In children reporting four or more intakes of sugars per day or three or more betweenmeal snacks per day, the caries scores markedly increased. For children that developed three or more lesions, the intake of sugars averaged 5.1 times per day at age five compared with 2.1 times a day for children who developed less than three carious lesions $(P<0.01)$. In an earlier cross-sectional study of 4 -year-old children in Iceland, Holbrook ${ }^{103}$ showed that caries levels markedly increased at frequency of intake of sugars above 30 times a week (approximately four times a day). Holt ${ }^{104}$, in a longitudinal study of English preschool children, found that dmft was higher (dmft 1.69) in children who had four or more sweetened snacks and drinks a day compared with children who only had them once a day (dmft 1.01). In this study, the relationship between total amount of sugars consumed and dmft was not investigated. The studies above suggest that if free sugars intake is limited to a maximum of four times a day, caries levels will be reduced.

Some studies have investigated the association between frequency of consumption of sugars-rich foods and caries development. A positive correlation between the frequency of consumption of confectionery and caries development was found in a study conducted on 900 14-year-old Caucasian, Hawaiian and Japanese schoolchildren in Hawaii ${ }^{105}$. Bjarnason et al. ${ }^{106}$ studied the relationship between dental caries levels and frequency of intake of sugary foods in children aged 12 and 13 from Iceland, using a dietary questionnaire. A higher caries incidence was associated with consumption of sweets and cakes at mealtimes and with frequency of confectionery consumption. In a study of longitudinal design, Sundin et $a l .{ }^{91}$ found that frequency of consumption of sweets was an important caries-related factor in Swedish teenagers. Caries incidence over a 3 year period was 
significantly related to frequency of intake of confectionery $(r=+0.25)$ and the relationship was stronger for teenagers with poor oral hygiene and a low salivary flow rate $(r=+0.7)$. The findings of Kalsbeek and Vereeps ${ }^{101}$, confirmed the association between the frequency of consumption of sugary snacks and the development of caries in children aged 5, 8 and 11 years. However, none of the above studies measured the amount of sugars consumed so the relationships between amount of sugars and caries levels in these studies were unknown. There are some studies that have found a lesser or no relationship between the dietary eating patterns of children and caries ${ }^{107-109}$.

\section{Amount of sugars}

Animal studies have also been used to investigate the relationship between amount of sugars consumed and the development of dental caries ${ }^{110,111}$. Mikx et al. ${ }^{110}$ found a significant correlation between the sugar concentration of the diet fed to rats and the incidence of dental caries. Hefti and Schmid ${ }^{112}$ found that dental caries severity increased with increasing sugars concentrations up a $40 \%$ sucrose diet. A number of epidemiological studies provide evidence for an association between amount of sugars consumed and dental caries and these are summarised in Table 10. Several longitudinal studies show amount of sugars intake to be more important that frequency ${ }^{95,96,113}$. Kleemola-Kujala and Rasanen ${ }^{82}$ found that dental caries increased with increasing amount of sugars consumption only when oral hygiene was poor.

Jamal et $a l .{ }^{114}$ related the amount of sugar added to tea and the frequency of consumption of sweetened tea to caries experience in children and young adults in Iraq. The number of cups of tea consumed and the amount of sugar added to tea were positively related with DMFT. The $r$-values obtained were +0.43 and +0.64 for urban and rural populations, respectively, for frequency of consumption and +0.55 and +0.71 , respectively, for amount of sugar. This study, therefore, supports the view that both the frequency and the amount of sugar intake are important.

There is, undoubtedly, a strong correlation between the amount and frequency of sugars consumption. In an analysis of dietary data from over 400 11-12 year-old children, Rugg-Gunn found the correlation between frequency of intake of sugars-rich foods and total weight consumed to be $+0.77^{95}$. Cleaton-Jones et al. ${ }^{115}$ reported significant associations between frequency and amount of sugar intake in a number of South African ethnic groups. Rodrigues et $a l .{ }^{116}$ found that nursery school children with a frequency of sugars intake of $4-5$ times per day were 6 times more likely to develop high caries levels over 1 year compared with children with the lowest frequency. In this study it was also shown that there was a direct relationship between amount and frequency of intake ${ }^{1}$. High correlations between the frequency of consumption and weight consumed of individual sugary foods such as chocolate $(+0.85)$ and sugared drinks $(+0.86)$ were also found. Ismail et al. ${ }^{117}$ also found a very high correlation between frequency of consumption of sugary drinks inbetween meals and amount consumed in American children $(r=+0.97)$ and reported that both increased frequency and amount were associated with higher caries risk. The odds ratios of having a DMFT of above the 80th percentile for age, increased from 1.28 for those having one soft drink per day to 1.87 for twice and 2.79 for three or more times a day.

In summary, there is evidence to show that both the frequency of intake of sugars and sugars-rich foods and drinks and the total amount of sugars consumed are both related to dental caries. There is also evidence to show that these two variables are strongly associated. In addition, oral hygiene standard, socio-economic status and fluoride exposure all influence the sugars-caries relationship.

\section{Different types of sugars}

Many of the earlier animal studies investigating the relationship between sugars and dental caries focused on sucrose, which was at that time the main dietary sugar that was added to the diet. However, modern diets of industrialised countries contain a mix of sugars and other carbohydrates including sucrose, glucose, lactose, fructose, glucose syrups, high fructose corn syrups and other synthetic oligosaccharides and highly processed starches that are fermentable in the mouth. Oral bacteria metabolise all mono and di-saccharides to produce acid and animal studies have shown no clear evidence that, with the exception of lactose, the cariogenicity of mono and disaccharide differs. However, early plaque $\mathrm{pH}$ studies have shown plaque bacteria produce less acid from lactose compared with other sugars ${ }^{118}$. Some animal studies have reported an increased cariogenicity of sucrose but in these studies the rats were super infected with $S$. mutans which utilises sucrose in preference to other sugars.

Studies in humans have also investigated the difference in the cariogenicity of some sugars for example the aforementioned Turku study showed no difference between the caries development between subjects on diets sweetened with sucrose compared with fructose ${ }^{26}$. The Malmo study which investigated the effect of substitution of sucrose with invert sugar (50\% fructose $+50 \%$ glucose) on caries development in preschool children in Sweden showed the cariogenicity of invert sugar to be $20-25 \%$ less that that of sucrose ${ }^{119}$.

\section{The form of sugar}

It is sometimes stated that the cariogenicity of sugary food is related to its stickiness. The longer it takes a food to clear the mouth the longer the drop in $\mathrm{pH}$ will remain. The adhesiveness or 'stickiness' of a food is not necessarily related to either oral retention time or cariogenic potential. There is evidence to show that the amount and frequency 
of consumption of high sugar drinks (with low stickiness/oral retention) are associated with increased risk of dental caries ${ }^{114,117}$.

\section{The influence of fluoride on the sugars-caries relationship}

Fluoride alters the resistance of the teeth to demineralisation as well as the speed with which the enamel surface remineralises following a plaque acid challenge. Fluoride affects the tooth post-eruptively in three ways. First, it reduces and inhibits demineralisation: Fluoride is incorporated into the enamel lattice and/or binds to enamel crystal surfaces and replaces the hydroxyl groups in hydroxyapatite. By converting hydroxyapatite into fluoroapatite which is more stable, fluoride reduces the susceptibility of the enamel to demineralisation. Second, remineralisation of enamel in the presence of fluoride results in the porous lesion being remineralised with fluoroapatite rather than hydroxyl apatite (the former being more stable and more resistant to further attack by acids). Lastly, fluoride also affects plaque by inhibiting bacterial metabolism of sugar thus reducing acid production. The main action of fluoride is topical at the enamel surface after eruption. The inverse relationship between fluoride in drinking-water and dental caries is well established ${ }^{120}$. Without any dietary modifications topical fluoride in either toothpaste, mouthrinses or varnishes reduces caries in children by between 20 and $40 \%$, but does not eliminate dental caries. Over 800 controlled trials of the effect of fluoride on dental caries have been conducted and show that fluoride is the most effective preventive agent against caries ${ }^{120}$. Widespread use of fluoride largely accounts for the decline in dental caries that has been observed in developed countries over the past three decades.

Much of the data that illustrate an association between intake of dietary sugars and dental caries were collected in the prefluoride era. More recent studies that attempt to focus only on the relationship between sugars and caries are confounded by the presence of fluoride but show that a relationship between sugars intake and caries still exists in the presence of fluoride. In two major longitudinal studies of the relationship between intake of dietary sugars and dental caries levels in children, the observed relationships between sugars intake and development of dental caries remained even after controlling for use of fluoride and oral hygiene practices ${ }^{95,96}$. In a crosssectional study of 12 -year-old children in the UK who were using fluoride toothpaste, DMFS scores were significantly related to the number of times sugary foods were consumed ${ }^{121}$. Holt et al. ${ }^{122}$ also found a relationship between frequency of sugars-rich snacks and caries levels in young children even after controlling for use of fluoride. Weaver ${ }^{61}$ reported on the fall in caries levels between 1943 and 1949 in 12-year-olds from areas with naturally high and low water fluoride concentration in North East
England. Caries levels were lower in the high fluoride area in 1943, but, following the war time sugar restriction, dental caries levels fell a further $54 \%$ indicating that exposure to fluoride did not totally override the effect of sugars in the diet. Likewise, Kunzel and Fischer ${ }^{123}$ also showed that the beneficial effects of fluoride vary according to levels of sugars consumed. Marthaler ${ }^{54}$ reviewed the changes in the prevalence of dental caries and concluded that, even when preventive measures such as use of fluoride are employed, a relationship between sugars intake and caries still exists. After reviewing the literature on declines in caries and associated factors Marthaler concluded that 'within modern societies which are aware and make use of prevention, the relationship between sugars consumption and caries activity still exists'. He also concluded that 'recent studies have demonstrated that sugar-sucrose as well as other hexoses-continues to be the main threat for dental health of (1) whole populations in some developed and many developing countries, (2) for the individual in both developed and developing countries and (3) in spite of the progress made in using fluorides and improved oral hygiene'. He also stated that, in Albania, Greece, Hungary, Iceland, Italy, Poland, Portugal, Spain and Yugoslavia, the high sugars consumption is still the most important determinant of caries prevalence. It is likely that, in industrialised countries where there is adequate exposure to fluoride, a further reduction in the prevalence and severity of dental caries will not be achieved without a reduction in free sugars intake.

A recent systematic review, Burt and $\mathrm{Pai}^{124}$ aimed to answer the question in the modern age of extensive fluoride exposure, do individuals with a high level of sugars intake, experience greater caries severity relative to those with a lower level of intake?' The review consisted of a search of MEDLINE and EMBASE databases for papers published between 1980 (an arbitrary starting point for the era of fluoride exposure) and 2000. The search produced 809 reports. Irrelevant reports and those that did not meet set inclusion criteria were discarded, to leave 69 reports of which 26 were cohort studies, 4 case-control studies, and 39 cross-sectional studies. Papers were then scored out of 100 according to scientific merit and those which scored 55 or higher-a total of 36-were included in the final analysis. In the final analysis, the risk of sugars-associated caries was rated according to the risk ratio (odds ratio,

Table 5 Distribution of 36 papers showing strong, moderate and weak relationships between sugars intake and dental caries by type of study design ${ }^{124}$

\begin{tabular}{lcccr}
\hline & Strong & Moderate & Weak & Totals \\
\hline Cohort studies & 1 & 7 & 4 & 12 \\
Case-control studies & 0 & 1 & 0 & 1 \\
Cross-sectional studies & 0 & 12 & 12 & 23 \\
Totals & 1 & 19 & 16 & 36 \\
\hline
\end{tabular}


relative risk) correlation coefficient or beta coefficient. The findings are summarised in Table 5.

There was only one paper classified as having a strong relationship between sugars intake and caries-a cohort study conducted in Brazil. However, over half of the papers found a moderate relationship and a further 16 found a weak relationship. No paper failed to find a relationship between sugars intake and caries. Twentythree of the papers were of cross-sectional design which is the weakest study design to address the question, the cohort design being the strongest. Out of the 12 cohort studies, 8 were of less than 2 years' duration. This may be an insufficient period to monitor the development of dental caries. The conclusions of the systematic review are that: (1) where there is good exposure to fluoride, sugars consumption is a moderate risk factor for caries in most people; (2) sugars consumption is likely to be a more powerful indicator for risk of caries in persons who do not have regular exposure to fluoride; (3) with widespread use of fluoride, sugars consumption still has a role to play in the prevention of caries but this role is not as strong as it is without exposure to fluoride.

\section{Fluoride intake and fluorosis}

Ingested fluoride affects the teeth preeruptively. An excess fluoride ingestion during enamel formation can lead to dental fluorosis and this condition is observed particularly in countries that have high levels of fluoride in water supplies. Reports indicate that the prevalence of dental fluorosis ranges from 3 to $42 \%$ in low fluoride areas and between 45 and $81 \%$ in areas with around $1 \mathrm{mg}$ fluoride/L water $^{1}$. Enamel fluorosis as well as skeletal fluorosis are found in large areas of India, Thailand, in the Rift Valley of East Africa and many Arab States.

\section{Starches and dental caries}

Starch constitutes a heterogeneous food group and it varies in botanical origin. It may be highly refined or consumed in its natural state, it is sometimes consumed raw (e.g. in fruits and vegetables) but is largely consumed in a cooked form. All these factors should be considered when assessing the potential and relative cariogenicity of starches. Some argue that cooked and processed starches enter into the caries process because starches are broken down by salivary amylase releasing glucose, maltose and maltotriose and that these are metabolised by oral bacteria to produce acids.

Plaque $\mathrm{pH}$ studies that use an indwelling plaque electrode tend to give an all or nothing response and are not good at discriminating the acidogenic potential between carbohydrates ${ }^{125}$. Studies using this method have shown starch-containing foods (e.g. white bread) can depress plaque $\mathrm{pH}$ below 5.5. Plaque $\mathrm{pH}$ studies that remove plaque from all areas of the mouth and then measure $\mathrm{pH}$ (harvesting method) are more discriminating and have shown that starch-containing foods are less acidogenic than sucrose or sucrose-rich foods. However, plaque $\mathrm{pH}$ studies measure acid production from a substrate and not caries development. This means plaque $\mathrm{pH}$ studies take no account of the protective factors found in some starch-containing food, nor do such studies account for the effect of foods on stimulation of salivary flow. Enamel slab experiments in humans have shown that raw starch does not cause demineralisation ${ }^{126}$ and that cooked starch is about one-third to one-half as cariogenic as sucrose ${ }^{127}$. Animal studies have shown that raw starch is of low cariogenicity ${ }^{128,129}$; cooked starch causes caries but only about half the amount caused by sucrose ${ }^{130}$. However, mixtures of starch and sucrose would seem to be potentially more cariogenic than starch alone and the level of caries that developed was related to the sucrose concentration in the mix $^{131}$. In a study using the rat model by Mundroff et al. ${ }^{132}$ intake of starch and lactose were not related to caries development whereas highly significant correlations between intake of glucose $(r=+0.43)$, reducing sugars $(r=+0.30)$, and sucrose $(r=+0.18)$ were found. Caution needs to be applied when extrapolating the results of animal studies to humans due to differences in tooth morphology, plaque bacterial ecology, salivary flow and composition and the form in which the diet is provided (usually powdered form in animal experiments). Nonetheless animal studies have enabled the effect on caries of defined types, frequencies and amounts of carbohydrates to be studied.

Epidemiological studies have shown that starch is of low risk to dental caries. People who consume high-starch/lowsugars diets generally have low caries experience whereas people who consume low-starch/high-sugars diets have high levels of caries. In the Hopewood House study ${ }^{75}$ children consumed a high-starch low-sugars diet and had low levels of caries. In the Turku study ${ }^{26}$ intake of starch was not limited and all groups ate unlimited starch yet low caries occurred in the xylitol (sugar free) group. Children with HFI have been shown to have low levels of caries, they cannot consume sucrose or fructose but can consume unlimited amounts of $\operatorname{starch}^{77}$. In a longitudinal study of diet and dental caries in 11-12-year-old English children, Rugg-Gunn et al. found no correlation between intake of starch and caries increment when controlling for sugars intake. Children with high-starch and low-sugars intakes had significantly fewer caries develop than children with low starch/high sugars intake ${ }^{95}$. Further evidence that starchy staple foods are of little importance in the development of caries comes from studies of dietary changes during the period of the Second World War. The intake of starch increased during this period in Norway and Japan yet the occurrence of caries was reduced. When sugars intake increased after the war, levels of caries also increased $^{59,133}$. Populations that habitually consume a high-starch/low-sugars diet have also been reported to have low levels of dental caries ${ }^{68,75,134,135}$. For example the Chinese and Vietnamese, Ethiopians and South 
American Indians have eaten cooked starches in the form of rice, wheat and maize but have a low sugars intake and low caries levels. The ecological study of Sreebny ${ }^{136}$, as well as comparing sugar availability and level of caries, compared the cereals availability and levels of caries in 12year-old children and found a correlation of +0.45 between wheat intake and DMFT. However, when the data were reanalysed by Rugg-Gunn ${ }^{79}$ to control for sugar availability the relationship between wheat availability and dental caries disappeared. When the relationship between sugar availability and caries experience was controlled for availability of wheat, the correlation was only reduced from +0.7 to +0.6 indicating that cereals availability did not affect caries experience but that sugar availability played a much more important role.

Less refined starchy staple foods (e.g. wholegrain foods) have properties that protect the teeth from decay. Wholegrain foods require more mastication and thereby stimulate increased secretion of saliva, increasing its buffering capacity. Unrefined plant foods also contain phosphates and there is some evidence that they convey a protective effect against demineralisation ${ }^{137,138}$.

Rugg-Gunn ${ }^{79}$ extensively reviewed the evidence on the relationship between starches and dental caries and concluded that:

- Cooked staple starchy foods such as rice, potatoes and bread are of low cariogenicity in humans.

- The cariogenicity of uncooked starch is very low.

- Finely ground and heat-treated starch can induce dental caries but the amount of caries is less than that caused by sugars.

- The addition of sugar increases the cariogenicity of cooked starchy foods. Foods containing cooked starch and substantial amounts of sucrose appear to be as cariogenic as similar quantities of sucrose.

Starches have become more processed and frequencies of eating may have increased in some countries. Many highly processed starchy foods are also relatively high in fats and or free sugars and salt (e.g. corn snacks, sweetened breakfast cereals, cakes and biscuits). It is not the intake of these but the increased intake of starchy staple foods (e.g. bread, potatoes and wholegrain foods) that is being encouraged.

\section{Fruit and dental caries}

In experimental conditions in which fruit is a major dietary constituent, fruits may participate in the caries process; however, as consumed as part of the mixed human diet there is little evidence to show fruit to be an important factor in the development of dental caries. A number of plaque $\mathrm{pH}$ studies have found fruit to be acidogenic (though less so than sucrose) ${ }^{139,140}$ although the extent of this varies according to texture and sugars content ${ }^{141}$. However, plaque pH studies measure acidogenicity and not cariogenicity and do not account for protective factors in fruits. These studies have also used an indwelling plaque $\mathrm{pH}$ electrode that tends to give a hypersensitive response. Animal studies have shown that, when fruit is consumed in high frequencies (e.g. 17 times a day) it may induce caries ${ }^{142,143}$. Animal studies revealed that all fruits cause less caries than sucrose. Epidemiological studies have shown that, as habitually consumed, fruit is of low cariogenicity. For example, a number of cross-sectional studies have compared dental caries experience to levels of fruit consumption. Savara and Suher ${ }^{144}$ in a study of children in the US, found no association between dental caries and the frequency of fruit consumption. KleemolaKujala and Rasanen ${ }^{145}$ in a study of Finnish children aged 5, 9 and 13 years found no differences in vitamin $\mathrm{C}$ intake (as an index of fruit consumption) between children with high compared to low caries and, likewise, Martinsson ${ }^{146}$ found no difference in intake of fruit between school children with high compared to low caries experience. In a study of longitudinal design, Clancy et $a l^{147}$ found a negative association between caries increment over 1 year and the consumption of apples and fruit juice. Similar findings were reported by Rugg-Gunn et al. ${ }^{95}$. The only epidemiological study in which an association between fruit consumption and dental caries was reported was that of Grobler and Blignaut ${ }^{148}$ who compared the dental caries experience of workers on apple and grape farms with workers on grain farms. The frequency of intake of fruit by the workers were very high; the workers on the apple farms consumed on average eight apples per day whereas the workers on the grape farms consumed on average three bunches of grapes per day. In both groups of fruit pickers, the mean DMFT was significantly higher than that of workers on the grain farm. However, the high DMFT levels were largely due to missing teeth, the cause of which was unknown, and the difference in DMFT between the grain and fruit farm workers was solely due to differences in the numbers of missing teeth.

Dried fruit may potentially be more cariogenic since the drying process breaks down the cellular structure of the fruit, releasing free sugars and dried fruits tend to have a longer oral clearance. Having extensively reviewed the evidence linking fruit consumption to dental caries, Rugg-Gunn concludes 'as eaten by humans, fresh fruit appears to be of low cariogenicity and citrus fruits have not been associated with dental caries'. He also concluded that, on present evidence, increasing consumption of fresh fruit in order to replace 'non-milk extrinsic sugars' (free sugars) in the diet is likely to decrease the level of dental caries in a population ${ }^{79}$.

\section{Novel carbobydrates and dental caries risk}

Glucose polymers (glucose syrups and maltodextrins) comprise a mixture of short chain saccharides and alphalimit dextrins and are increasingly being added to foods in industrialised countries. Evidence on the cariogenicity of these carbohydrates is sparse and comes from animal 
studies, plaque $\mathrm{pH}$ studies and studies in vitro which suggest that maltodextrins and glucose syrups are cariogenic $^{149-151}$. The use of synthetic non-digestible oligosaccharides (prebiotics) is also increasing. Plaque $\mathrm{pH}$ studies and experiments in vitro suggest that isomaltooligosaccharides and glucooligosaccharides may be less acidogenic compared with sucrose ${ }^{152-154}$. However, there is evidence that fructooligosaccharides, which are more widely available in foods, are as acidogenic as sucrose $\mathrm{s}^{155,156}$.

\section{Factors that protect against dental caries}

Plaque pH studies have shown that consuming cheese following a sugary snack virtually abolishes the usual fall in $\mathrm{pH}$ that is associated with sugars consumption ${ }^{157}$. Cheese stimulates salivary secretion and increases plaque calcium concentration $^{157}$. The calcium concentration of dental plaque strongly influences the balance between deand remineralisation of enamel. In an epidemiological study, cheese intake was higher in children who remained caries-free over a 2-year period than in those who developed caries $^{95}$. Furthermore, Gedalia and colleagues $^{158}$, in a controlled clinical trial in children, demonstrated that eating a $5 \mathrm{~g}$ piece of hard cheese daily, following breakfast, for a period of 2 years, resulted in the development of significantly less caries.

Cows' milk contains lactose and also calcium, phosphorus and casein all of which are thought to inhibit caries. Several studies have shown that the fall in plaque $\mathrm{pH}$ following cows' milk consumption is negligible ${ }^{159,160}$. There is some evidence from animal studies that the addition of cows' milk to a cariogenic diet reduced the caries incidence ${ }^{161}$. Bowen ${ }^{162}$ showed that desalivated rats (i.e. caries prone) remained more or less caries-free when fed cows' milk compared to those fed sucrose or lactose in water, and concluded that cows' milk can be used safely by patients with low salivary flow as a saliva substitute. Rugg-Gunn et al..$^{95}$ found an inverse relationship between the consumption of cows' milk and caries increment in a study of English adolescents.

In line with the overall positive health effects of breastfeeding, epidemiological studies have associated breastfeeding with low levels of dental caries ${ }^{104,163}$. A few specific case studies have linked prolonged ad libitum and nocturnal breastfeeding to early childhood caries. Breastfeeding has the advantage that it does not necessitate the use of a feeder bottle, which has been associated with early childhood caries. A breastfed infant will also receive milk of a controlled composition to which additional free sugars may not be added. There are no benefits to dental health of feeding using a formula feed.

The effects on caries of factors in foods of plant origin including organic phosphates, inorganic phosphates, and phytate have been investigated. Both organic and inorganic phosphates have been found to be effective in animal studies, but studies in humans have produced inconclusive results ${ }^{138,164}$. When isolated from foods, phytate is an effective anti-caries factor but as an intrinsic food component is not effective ${ }^{79}$. The main reason that fibrous foods protect the teeth is because they mechanically stimulate salivary flow. Other foods that are good gustatory and/or mechanical stimulants to salivary flow are peanuts, hard cheeses and chewing gum.

Black tea contains fluoride, polyphenols and flavanoids. Both animal studies and experimental investigations in humans show that black tea extract increases plaque fluoride concentration and reduces the cariogenicity of a sugars-rich diet ${ }^{165,166}$.

\section{Classification of sugars and carbobydrates for dental bealth and general bealth purposes}

The term 'free sugars' includes all added sugars (by manufacturer, cook or consumer) but also includes sugars present in fruit juices, honey and syrups. For dental health and general health purposes it is important to distinguish between sugars naturally present in fruits, vegetables, grains and milk as the evidence shows that these foods are not associated with dental caries. The consumption of these foods is also desirable, whereas the consumption of foods rich in free sugars is not. If the intake of free sugars were limited and the intake of fruit, vegetables, wholegrains and starch rich staple foods increased, it is highly likely that dental decay would be reduced.

\section{Is there an inverse relationship between the intake of free sugars and fat in the diet?}

It is important to consider the effect that changing one aspect of the diet has on other components of the diet. With respect to this, cross-sectional analysis of dietary data from populations has shown an inverse relationship between the intake of free sugars and the intake of fat ${ }^{167}$. This has led to the argument that reducing the intake of free sugars might lead to an increase in fat in the diet and has sometimes resulted in targets for free sugars not being set. However, cross-sectional analysis is not an accurate means of investigating the effect of a change in intake of one dietary constituent on the intake of other dietary constituents. More recent longitudinal data from studies that have monitored dietary changes and the influence that changing one constituent has on other nutrients do not support the hypothesis for an inverse relationship between the intake of free sugars and fat. There is a growing body of evidence from such longitudinal research that shows that changes in intake of fat and sugar are not inversely related. Fletcher et al. ${ }^{168}$, in a repeated crosssectional study, found that fat intake by adolescents decreased over a 10 year period and the calories from fat were balanced by an increase in the intake of starch whereas free sugars intake did not increase. Likewise, Alexy et al. ${ }^{169}$ showed that between 1985 and 2000 the intake of fat by German children has significantly decreased and that the calories were replaced with 
carbohydrates other than added sugars, the intake of added sugars remaining stable. In a relatively short-term dietary intervention study to increase fibre intake, ColeHamilton et $a l^{170}$ found both fat and added sugar to simultaneously decrease while fibre intake increased. Most recent evidence does not support the idea of an inverse relationship between intake of free sugars and fat and furthermore overall dietary goals that promote increased intake of wholegrain staple foods, fruits and vegetables and a reduced consumption of free sugars are unlikely to lead to an increased consumption in fat.

\section{Diet and dental erosion}

The evidence for an aetiological role of diet in the development of dental erosion comes from clinical trials, human observational studies, experimental clinical studies, animal studies, case reports and experiments in vitro. Thomas ${ }^{171}$ showed that dental students who consumed either grapefruit juice, orange juice or cola daily for 6 weeks had signs of erosion on their labial incisors and that this was greatest with grapefruit juice. Stabholz et al. ${ }^{172}$ studied the exfoliated deciduous teeth of children who had received orange juice at school daily for 10-18 months and found that the teeth showed slight demineralisation.

Epidemiological observational studies have shown an association between dental erosion and the consumption of a number of acidic foods and drinks including frequent consumption of vinegar and pickles, citrus fruits and berries ${ }^{173}$ and consumption of fruit juice at bedtime ${ }^{174}$. It has also been shown that frequency of intake of acidic beverages and foods is a more important determinant of erosion than total amount consumed and also that erosion tends to occur in individuals with good oral hygiene ${ }^{47}$. Jarvinen et ll $^{46}$, in a case-control study, found that the dietary practices associated with erosion were consumption of citrus fruits twice or more per day, consumption of soft drinks once per day and consumption of vinegar or sports drinks more than once a week. Other risk factors included eating disorders (largely due to effect of intrinsic acids on vomiting), gastro-oesophageal reflux and a low salivary flow rate. The UK NDNS of young people aged 4-18 years showed that the prevalence of erosion increased with age in high, moderate and low bands of soft drink consumption. The age-related increase was greatest in the highest bands of soft drink consumption. For those in the upper band of consumption, the proportion who had erosion increased from 28 to $52 \%$ between ages $7-10$ and 11-14, whereas in the lowest band of consumption erosion increased from 27 to $39 \%$ between these two age groups ${ }^{52}$.

Experimental clinical studies have shown that consumption of, or rinsing with, acidic beverages significantly lowers the $\mathrm{pH}$ of the oral fluids and this is most marked with grapefruit juice ${ }^{141}$. Enamel slab experiments have shown that enamel is softened within $1 \mathrm{hr}$ of exposure to cola but this may be reversed by exposure to milk or cheese $^{175,176}$. Animal studies have looked at the effect of acidic food and drink consumption on demineralisation of rat molars. Stephan ${ }^{143}$ reported that fruit and soft drinks caused erosion and Holloway et al. ${ }^{177}$ showed that fruit drinks cause erosion to the teeth of rats and dogs. Miller ${ }^{178}$ made the important observation that fruit juices were 3-10 times more destructive than whole fruit in rats. However, due to differences in drinking technique and salivary flow and composition, there are difficulties in extrapolating the findings of these studies to humans.

Many of the reports on diet and erosion have been single case reports and have shown that extensive erosion has been associated with sucking lemon wedges ${ }^{179}$, drinking cola continuously or holding cola in the mouth $^{180,181}$, addition of baby fruit juices to comforters or reservoir feeders ${ }^{182}$, or mega doses of chewable vitamin $\mathrm{C}^{183}$.

In vitro experiments supplement the clinical evidence for an association between diet and erosion but vary wide in methodology. However, in general such studies have shown that beverages with a high titratable acidity or a $\mathrm{pH}$ of $<4$ can lead to erosion. Fruit juices have also been shown to be more erosive than pulped fruits ${ }^{184}$. Citric, malic and tartaric acids are particularly erosive ${ }^{185}$ and carbonic acid is the least erosive ${ }^{46}$. However, Meurman and Cate ${ }^{21}$ argue that present data does not allow the ranking of different acids.

In summary, erosion appears to be an increasing problem in industrialised countries and is related to extrinsic and intrinsic acids. Levels observed in industrialised countries are thought to be due to increased consumption of acidic beverages (i.e. soft drinks and fruit juices). Fruit juices are more erosive than whole fruits and consumption of the former has increased markedly over recent years in industrialised countries. For example, in the UK, there has been an 800-fold increase in the consumption of soft drinks since the $1950 \mathrm{~s}^{186}$. In order to reduce the prevalence of erosion the frequency of acidic beverages needs to be reduced and/or the resistance to erosion needs to be increased. Factors such as salivary flow, fluoride, calcium and phosphate may protect against erosion although there is no consensus as to how effective these factors are in prevention. Overall, there is a need for more comprehensive population-based studies on the prevalence of dental erosion using a standard index of measurement. The longitudinal patterns of the dental erosion in populations needs to be monitored and related to changes in dietary factors (e.g. soft drink consumption).

\section{Summary of the strengths and weaknesses of the evidence}

The strength of the evidence linking dietary sugars to dental caries risk is in the multiplicity of the studies rather than the power of any individual study. Strong evidence is 
provided by the intervention studies (Vipeholm and Turku studies $^{78}$ but the weakness of these studies is that they were conducted in the prefluoride era. Today it would not be possible to repeat these intervention studies due to more stringent ethical codes. Many of the studies showing an association between sugars intake and dental caries were carried out in the prefluoride era. The fact that exposure to fluoride has not totally eradicated the relationship between sugars and caries has already been addressed. It must also be noted that many populations of developing countries are not yet exposed to fluoride but are increasingly exposed to a higher consumption of amount and frequency of free sugars and other fermentable carbohydrates in the diet. Fluoride undoubtedly decreases caries risk yet it does not always balance out the dietary factors involved in caries formation.

Many of the studies that have investigated an association between diet and dental caries are cross-sectional in design. As caries is a progressive disease that occurs over a period of time it is probable that it was the diet factors several years earlier that helped achieve the present disease levels. Longitudinal studies that have monitored a change in caries and related this to diet factors provide stronger evidence than cross-sectional studies but are relatively rare. Those that exist have studied populations with an overall high sugars intake with a low interindividual variation. This probably accounts for the weak associations that have been reported.

The studies that overcome the problem of a low range of inter-subject variation are times series studies that have monitored dental caries following a marked change in diet, for example, those conducted during the Second World War years and studies of populations before and following introduction of sugars into the diet. These have shown clearly that changes in dental caries mirror changes in economic growth and increased sugars consumption. Some reports have argued that the changes in sugars intake did not occur in isolation and that intake of refined starches also changed, claiming that all carbohydrates can participate in development of dental caries. However, there are examples where sugars intake decreased and starch intake increased yet levels of dental caries declined.

Strong evidence of the relationship between sugar availability and dental caries levels comes from the ecological studies of Sreebny ${ }^{53}$ and Woodward and Walker $^{55}$. The limitations of these studies are that they use sugar availability data and not actual intake, they do not measure daily frequency of sugars ingestion and assume that level of intake is equal throughout the population. The values are also for sucrose, yet many countries obtain a considerable amount of their total sugars from other free sugars such as high fructose corn syrup in the US and glucose in Ireland. These studies have only considered DMFT of 12-year-olds (not always from a representative sample of the population) and not other age groups so there is little information on the effect of sugars availability on caries levels in adults and the progression of the disease.

Information from animal studies, experimental plaque $\mathrm{pH}$ studies and enamel slab experiments provides insights into the information that cannot be obtained from the epidemiological studies. Data from animal studies have enabled investigation of the effect on caries of different concentrations and frequencies of different types of sugars and fermentable carbohydrates. However, these experiments have mostly been conducted on rats, which differ in tooth morphology and salivary composition to humans and the experimental diets are often fed in a powered form with eating and drinking techniques that are different to humans.

Plaque $\mathrm{pH}$ studies measure plaque acid production following consumption of a substance but not caries development. Therefore, they do not take into account protective factors in foods and the effects of other components of the diet. Many of the plaque $\mathrm{pH}$ studies that show falls in $\mathrm{pH}$ below the critical $\mathrm{pH}$ of 5.5 with cooked starchy foods have been conducted using the indwelling electrode technique in order not to disturb the plaque. However, the indwelling electrode is recognised as being a hypersensitive and non-discriminating, tending

Table 6 Summary of the strengths and weaknesses for the evidence linking diet to dental caries

\begin{tabular}{|c|c|c|c|}
\hline & Increased caries & No relationship & Decreased caries \\
\hline \multirow[t]{2}{*}{ Convincing } & $\begin{array}{l}\text { Frequency of intake } \\
\text { of free sugars }\end{array}$ & $\begin{array}{l}\text { Starch intake (cooked and raw starch } \\
\text { foods, such as rice, potatoes and } \\
\text { bread. Excludes cakes, biscuits and snacks } \\
\text { with added mono and/or disaccharides) }\end{array}$ & Fluoride exposure \\
\hline & Amount of free sugars & - & \\
\hline Probable & - & Whole fresh fruit & $\begin{array}{l}\text { Hard cheese } \\
\text { Sugar-free chewing gum }\end{array}$ \\
\hline Possible & Undernutrition & - & $\begin{array}{l}\text { Xylitol } \\
\text { Milk } \\
\text { Dietary fibre }\end{array}$ \\
\hline Insufficient & Dried fruits & - & Whole fresh fruit \\
\hline
\end{tabular}


Table 7 Summary of the strengths and weaknesses of the evidence linking diet to dental erosion

\begin{tabular}{lccc}
\hline & $\begin{array}{c}\text { Increased risk } \\
\text { of erosion }\end{array}$ & $\begin{array}{c}\text { No } \\
\text { relationship }\end{array}$ & $\begin{array}{c}\text { Decreased } \\
\text { risk of erosion }\end{array}$ \\
\hline $\begin{array}{l}\text { Convincing } \\
\text { Probable }\end{array}$ & $\begin{array}{c}\text { Soft drinks and } \\
\text { fruit juices }\end{array}$ & - & - \\
Possible & - & - & - \\
Insufficient & Fresh whole fruit & - & $\begin{array}{c}\text { Hard cheese } \\
\text { Fluoride }\end{array}$ \\
\hline
\end{tabular}

Table 8 Summary of the strengths and weaknesses of the evidence linking diet to enamel developmental defects

\begin{tabular}{lccc}
\hline & Increased risk & No relationship & Decreased risk \\
\hline Convincing & Excess fluoride & - & Vitamin D \\
Probable & Hypocalcaemia & - & - \\
\hline
\end{tabular}

Table 9 Summary of the strengths and weaknesses of the evidence linking diet to periodontal disease

\begin{tabular}{|c|c|c|c|}
\hline & $\begin{array}{l}\text { Increased } \\
\text { risk }\end{array}$ & $\begin{array}{l}\text { No } \\
\text { relationship }\end{array}$ & $\begin{array}{l}\text { Decreased } \\
\text { risk }\end{array}$ \\
\hline Convincing & $\begin{array}{l}\text { Deficiency of } \\
\text { vitamin C }\end{array}$ & - & $\begin{array}{l}\text { Good oral } \\
\text { hygiene } \\
\text { Absence of } \\
\text { plaque }\end{array}$ \\
\hline $\begin{array}{l}\text { Probable } \\
\text { Possible }\end{array}$ & Undernutrition & $\begin{array}{l}- \\
-\end{array}$ & $\begin{array}{l}- \\
-\end{array}$ \\
\hline Insufficient & Sucrose & $\begin{array}{l}\text { Vitamin E } \\
\text { supplementation }\end{array}$ & $\begin{array}{l}\text { Antioxidant } \\
\text { nutrients } \\
\text { Fibrous foods }\end{array}$ \\
\hline
\end{tabular}

to give an 'all or nothing' response to all carbohydrates ${ }^{125}$. The evidence for a link between diet and dental diseases is summarised in Tables 6-9.

\section{Policy implications_potential strategies}

\section{Strategies to prevent dental caries: modification of free sugars consumption}

A summary of the research indicating theoretical safe/ acceptable levels of intake for free sugars is given in Table 10. It is important at the population level to have a maximum level of intake for free sugars because a wealth of evidence shows that when free sugars intake by a population is low, dental caries levels are low. A population goal based on amount of free sugars intake also enables the dental health risks of populations to be assessed and health promotion goals monitored.

There is some evidence that the relationship between dental caries and levels of sugar is S-shaped 187,188 (Table 10). At low levels of sugar intake $(\leq 10 \mathrm{~kg} /$ person $/ \mathrm{yr}(27.4 \mathrm{~g} / \mathrm{d}))$ dental caries is very low. When annual sugar consumption is above $15 \mathrm{~kg} /$ person/yr $(40 \mathrm{~g} / \mathrm{d})$ dental caries increases and intensifies with increasing sugar availability. At high levels of sugar intake (approximately $35 \mathrm{~kg} /$ person/yr $(96 \mathrm{~g} /$ person/d)) the curve flattens out and a saturation level is reached, so that a further increase in sugar beyond this level does not increase caries to any appreciable extent. The benefits of decreasing free sugars may, therefore, be larger at high levels of intake just below the saturation level. The studies summarised in Table 10 were largely based on epidemiological study designs, using sugar availability data in populations that were not necessarily exposed to fluoride. Exposure to fluoride in some countries has altered the sugars caries relationship and widespread exposure to fluoride may increase the level of safe intake. Sheiham ${ }^{189}$ argues that where fluoride in drinking-water is at $0.7-$ $1 \mathrm{ppm}$, or where over $90 \%$ of toothpastes available are fluoridated, the sugars caries relationship shifts and increases the safe level of sugars consumption from $10 \mathrm{~kg} /$ person/yr to $15 \mathrm{~kg} /$ person/yr.

\section{Policies on sugars intake in different countries}

A number of countries have adopted policies/recommendations for free sugars (also referred to as 'added' 'purified' 'non-milk extrinsic' or 'refined') intake based on these data-these are summarised in Table 11. The 1990 WHO report 'Diet, Nutrition and the Prevention of Chronic Diseases' also recommended that free sugars should contribute no more than $10 \%$ to energy intake ${ }^{190}$. Freire et $a l .{ }^{191}$ conducted a worldwide review of national recommendations for sugars intake and found that 23 countries had set goals for sugars consumption.

\section{Fluoride in caries prevention}

Fluoride is an important preventive agent against dental caries and more efforts are needed to ensure that the majority of populations are exposed to optimum fluoride concentrations in water and that fluoride toothpastes are available. Exposure to fluoride alone may not eliminate caries but, along with reduction in free sugars intake, it has a significant effect on caries prevention. Research into effective means of delivering optimum exposure to fluoride should continue. It is important to note that many countries that are currently undergoing nutrition transition do not have adequate exposure to fluoride.

\section{Promotion of good oral bygiene}

There is no strong evidence of a clear relationship between oral cleanliness and levels of dental caries ${ }^{192}$. The Health Education Authority in England concluded that 'although caries cannot develop without the presence of plaque, plaque removal by tooth brushing cannot in itself be advocated for caries prevention. Normal brushing inevitably leaves some plaque in fissures and in other stagnation sites where caries occurs and plaque rapidly begins to reform on cleaned tooth surfaces. While toothbrushing is important for maintaining gingival health, numerous studies have failed to establish a clear association between toothbrushing and caries incidence. However, brushing with a fluoride toothpaste is the most 
Table 10 Summary of the evidence for low levels of intake of free sugars

\begin{tabular}{|c|c|c|c|c|}
\hline $\mathrm{Kg} /$ person/yr & g/person/d & Author & Caries levels & \\
\hline- & 0 & Takahashi $^{195}$ & $\begin{array}{l}\text { No caries. Annual caries } \\
\text { increment was positively related } \\
\text { to sugars when annual } \\
\text { sugar intakes ranged from } \\
0.2-15 \mathrm{~kg}(r=+0.8)\end{array}$ & Data from Japan \\
\hline 0 & 0 & Turku study $^{26}$ & $\begin{array}{l}56 \% \text { less caries when } \\
\text { xylitol replaced sucrose }\end{array}$ & Intervention study, Finland \\
\hline$<3.6$ & $<10$ & Ruxton et al. ${ }^{57}$ & Change in DMFT $<1$, over 8 years & WHO database \\
\hline$<10$ & $<30$ & Sheiham $^{188}$ & $\begin{array}{l}\text { Caries low (if little } \\
\text { fluoride exposure) }\end{array}$ & WHO database \\
\hline$<10$ & $<30$ & Takeuchi $^{196}$ & $\begin{array}{l}\text { Seldom caries in first } \\
\text { two post eruptive years } \\
\text { in first molars }\end{array}$ & - \\
\hline$>12.3$ & $>33$ & Rodriguez $^{116}$ & $\begin{array}{l}\text { Caries in deciduous dentition } \\
29 \% \text { more likely }\end{array}$ & Preschool children in Brazil \\
\hline$<10$ & $<30$ & Woodward and Walker ${ }^{55}$ & $\begin{array}{l}78 \% \text { of countries had } \\
\text { DMFT }<2 \text { and } 30 \% \text { with } \\
>10 \mathrm{~kg} / \mathrm{yr} \text { had DMFT }<2.0\end{array}$ & WHO database \\
\hline$<10$ & $<30$ & Knowles $^{197}$ & $>50 \%$ of $3-7$ year-olds were caries-free & $\begin{array}{l}\text { War-time data, children in } \\
\text { Jersey/England }\end{array}$ \\
\hline$<15$ & $<40$ & Sheiham $^{188}$ & $\begin{array}{l}\text { Caries low if fluoride } \\
\text { exposure }\end{array}$ & WHO database \\
\hline$<15$ & $<40$ & Miyazaki and Morimoto 62 & $\begin{array}{l}\text { DMFT }<3.0 \text {. Caries levels increased } \\
\text { as sugars intake increased } \\
\text { until a peak was } \\
\text { reached at } 29 \mathrm{~kg} / \mathrm{yr} \text { in } 1973 . \text { Thereafter, } \\
\text { sugar intake decreased and } \\
\text { so did caries. Correlation } \\
\text { between sugar intake and } \\
\text { caries was significant and } \\
\text { high }(r=+0.9)\end{array}$ & Data from Japan 1945-1987 \\
\hline$>15$ & $>40$ & Takeuchi $^{196}$ & $\begin{array}{l}\text { Caries occurred in first } \\
\text { post eruptive year and } \\
\text { intensified }\end{array}$ & Data from Japan 1941-1958 \\
\hline 10.4 & 28.5 & Schulerud $^{198}$ & $\begin{array}{l}\text { Good dental health in } \\
6-12 \text {-year-old children }\end{array}$ & War-time data from Norway \\
\hline$<20$ & $<55$ & Buttner $^{199}$ & Caries very low & $\begin{array}{l}\text { Data from } 18 \text { countries } \\
\text { in } 1959\end{array}$ \\
\hline$<18.25$ & $<50$ & Sreebny ${ }^{53}$ & DMFT $<3.0$ & WHO database \\
\hline$<18.25$ & $<50$ & Woodward and Walker ${ }^{55}$ & DMFT $<3$ in $23 / 26$ countries & WHO database \\
\hline
\end{tabular}

Table 11 Policies on intake of 'free sugars' by a number of countries

\begin{tabular}{lll}
\hline 1986 & Netherlands, Ministry of Health & $0-10 \%$ \\
1987 & Australia, Department of Health & $\leq 12 \%$ \\
1987 & Finland, Nutrition Board & $\leq 10 \%$ \\
1989 & Poland, National Institute & $<10 \%$ \\
1991 & United Kingdom, Department of Health & $\leq 10 \%$ \\
1996 & Nordic Nutrition Recommendations & $\leq 10 \%$ \\
1997 & Sweden & $\leq 10 \%$ \\
\hline
\end{tabular}

important method for delivering fluoride to the tooth surface. Other methods for plaque removal such as eating fibrous foods including apples and carrots are ineffective ${ }^{, 193}$. In an extensive review of epidemiological data concerning the role of oral hygiene in caries prevention, Sutcliff concluded 'although toothcleaning with unmedicated agents may be expected to reduce caries experience, the lack of consistent epidemiological corroboration of the relationship has led to questioning of the value of oral hygiene practices against caries. Relatively few controlled prospective studies have been undertaken and the results point towards a weak positive association between plaque and dental caries. Toothbrushing with fluoride toothpastes has been shown to be an effective caries preventive measure ${ }^{, 194}$.

Recommendations for prevention of dental diseases It is important that there is a recommended maximum level for consumption of free sugars because when free sugars consumption by a population is low, dental caries levels are low. Population goals enable the oral health risks of populations to be assessed and health promotion goals monitored.

The best available evidence indicates that the level of dental caries is low in countries where the consumption of free sugars is below $15-20 \mathrm{~kg} /$ person/yr. This is equivalent to a daily intake of $40-55 \mathrm{~g}$ and the values equate to $6-10 \%$ of energy intake. It is of particular importance that countries which currently have low consumption of free sugars $(<15-20 \mathrm{~kg} /$ person/yr) do not increase consumption levels. For countries with high consumption levels, it is recommended that national health authorities and 
decision makers formulate country-specific and community-specific goals for reduction in the amount of free sugars, aiming towards the recommended maximum of no more than $10 \%$ of energy intake, in addition to the development of oral health programmes to protect from dental caries.

In addition to population targets given in terms of amount of free sugars, targets for frequency of free sugars consumption are also important. The frequency of consumption of foods and/or drinks containing free sugars should be limited to a maximum of four times per day.

Many countries that are currently undergoing nutrition transition do not have adequate exposure to fluoride. There should be promotion of adequate fluoride exposure via appropriate vehicles, for example affordable toothpaste, water, salt and milk. It is the responsibility of national health authorities to ensure implementation of feasible fluoride programmes for their country. Research into the outcome of alternative community fluoride programmes should be encouraged.

In order to minimise the occurrence of dental erosion, the amount and frequency of intake of soft drinks and juices should be limited. Elimination of undernutrition prevents enamel hypoplasia and the other potential effects of undernutrition on oral health (e.g. salivary gland atrophy, periodontal disease, oral infectious diseases).

\section{Recommendations to international organisations for the prevention of dental diseases}

The potential financial consequence of failing to prevent dental diseases need to be highlighted, especially to governments of countries that currently have low levels of disease but are undergoing nutrition transition. The detrimental impact of quality of life throughout the life course and the longer-term nutritional consequences of dental disease and tooth loss also need to be highlighted.

The WHO should encourage and aid the regular monitoring of the prevalence and severity of dental disease (e.g. caries, erosion) in different age groups and the prevalence of tooth loss in different countries. The WHO and FAO should also aid the collection of national information on the amount and frequency of dietary free sugars and soft drink intake and should provide guidance to nations on standardised methods for data collection on appropriate study populations where necessary.

The WHO should promote efforts to address identification of suitable means of delivering optimum fluoride to countries where exposure is inadequate.

The WHO and other international organisations should recognise nutrition as an essential part of training for dental health professionals, and dental health issues, an important component of the education of nutritionists and other health professionals. This is essential if advice for dental health is to be consistent with dietary advice for general health.

\section{Recommendations to governments and intersectoral ministries}

Governments should set strategies to implement the recommendations of the report of the joint WHO/FAO expert consultation on Diet and the prevention of chronic diseases and should support food-based dietary guidelines. Governments should establish the means of monitoring the severity and prevalence of oral diseases and the risk factors associated with them (e.g. free sugars intake) and should adopt global standard guidelines for methods of data collection where available. These data should be made available to the WHO to enable continuous updating of the WHO oral health database.

Governments should support research into elucidating optimum fluoride intake by different age groups and effective means of delivering optimum fluoride and should also support research into nutrition and dental health relevant to countries' needs e.g. research into effective means of dietary intervention for dental health.

Governments should ensure that teachers, pupils and health professionals receive adequate education on diet, nutrition and dental health issues. Governments should also provide guidelines for the use of and content of educational materials to ensure they are sound and nonbiased.

Governments should set more stringent codes of practice on advertising (including advertising and information on the Internet) of sugars-rich items.

\section{Recommendations to private sector and industry}

Food manufacturers should continue to produce lowsugars/sugars-free alternatives to products rich in free sugars, including drinks. Manufacturers should also look at means to reduce the erosive potential of soft drinks.

To enable individuals to make informed choices regarding the oral health/dental problems related to high and frequent free sugars intake, there is a need for clear and unbiased labelling of foods with respect to sugars contents.

\section{Recommendations to civil society}

Oral health education should be included in nutrition education at schools and at antenatal classes where available, and should be based on sound non-biased information. Oral health education should be promoted alongside other forms of health education and dietary and nutrition advice for oral health should be integrated with advice for general health. Health education campaigns and health promotion websites should be encouraged.

\section{Recommendations at the level of the individual}

Individuals should be recommended to reduce the frequency with which they consume foods containing free sugars to four times a day and thereby limit the amount of free sugars consumed. In countries where fluoride toothpaste is available/affordable, individuals should be encouraged to brush their teeth with a fluoride toothpaste twice a day. 


\section{Areas for more information/research}

The areas identified where there is a need for more research and/or information are as follows:

1. More information is required on the intake of free sugars and fermentable carbohydrates, and the dietary sources of these carbohydrates, by different populations and age groups, especially in countries undergoing economic growth and nutrition transition.

2. More information is needed from longitudinal studies or repeated cross-sectional studies (e.g. from countries undergoing nutrition transition) of the relationship of change in fat intake to the change in free sugars intake.

3. Research into the optimum fluoride ingestion for different ages, climates and nutritional status should be encouraged.

4. More information is needed on the prevalence of severity of dental erosion using standardised methods of data collection, to enable monitoring of changes in levels of erosion with time.

5. The levels of consumption of soft drinks and fruit juices and other acid-containing foods needs to be monitored.

6. Effective means of promoting increased consumption of fruits, vegetables and NSP-rich diets in subjects with compromised dental status (e.g. the edentulous) need to be developed and evaluated.

\section{Acknowledgements}

An earlier version of this paper was prepared as a background paper for the Joint WHO/FAO Expert Consultation on diet, nutrition and the prevention of chronic diseases (Geneva, 28 January-1 February 2002). The authors would like to thank Dr Lois K. Cohen from National Institute of Dental and Craniofacial Research, NIH, Bethesda, MD, USA; Professor Andrew Rugg-Gunn from the School of Dental Sciences, University of Newcastle upon Tyne, Newcastle upon Tyne, UK; Dr Stephen Moss from Health Education Enterprises, Inc., New York, NY, USA; Professor Aubrey Sheiham from University College London, London, UK; and Dr Peter Lingström from University of Göteborg, Göteborg, Sweden, for their comments on an earlier draft of the manuscript.

\section{References}

1 Sheiham A. Dietary effects on dental diseases. Public Health Nutrition 2001; 4: 569-91.

2 Wang H-Y, Petersen PE, Jin-You B, Bo-Xue Z. The second national survey of oral health status of children and adults in China. International Dental Journal 2002; 52: 283-90.

3 Petersen PE, Hoerup N, Poomviset N, Prommajan J, Watanapa A. Oral health status and oral health behaviour of urban and rural schoolchildren in Southern Thailand. International Dental Journal 2001; 51: 95-102.

4 Petersen PE, Razanamihaja N. Oral health status of children and adults in Madagascar. International Dental Journal 1996; 46: 41-7.

5 Petersen PE, Kaka M. Oral health status of children and adults in the Republic of Niger, Africa International Dental Journal 1999; 49: 159-64.

6 World Health Organization. Global Oral Health Data Bank. Geneva: World Health Organization, 2001.

7 Chen M, Andersen RM, Barmes DE, Leclercq M-H, Lyttle SC. Comparing Oral Health Systems. A Second International Collaborative Study. Geneva: World Health Organization, 1997.

8 Kelly M, Steele J, Nuttall N, Bradlock G, Morris J, Nunn J, et al. Adult Dental Health Survey. Oral Health in the United Kingdom 1998. London: The Stationery Office, 2000.

9 Minquan D, Petersen PE, Fan MW, Tan BJ, Zhuan B. Oral health services in PR China as evaluated by dentist and patients. International Dental Journal 2000; 50: 175-83.

10 Rajab LD, Petersen PE, Bakaeen G, Hamdan MA. Oral health behaviour of schoolchildren and parents in Jordan. International Journal of Paediatric Dentistry 2002; 12 : 168-76.

11 Petersen PE, Poulsen VJ, Ramahaleo JJ, Ratsifaritara C. Dental caries and dental health behaviour situation among 6- and 12-year old urban schoolchildren in Madagascar. African Dental Journal 1991; 5: 1-7.

12 Moynihan PJ, Snow S, Jepson NJA, Butler TJ. Intake of nonstarch polysaccharide (dietary fibre) in edentulous and dentate persons: an observational study. British Dental Journal 1994; 177: 243-7.

13 Steele JG, Sheiham A, Marcenes W, Walls AWG. National Diet and Nutrition Survey: People Aged 65 Years and Over. Volume 2: Report of the Oral Health Survey. London: The Stationery Office, 1998.

14 Joshipura KJ, Willett WE, Douglass CW. The impact of edentulousness on food and nutrient intake. Journal of the American Dental Association 1966; 129: 1261-9.

15 Moynihan PJ, Butler TJ, Jepson NJA. Nutrient intake in partially dentate patients: the effect of prosthetic rehabilitation. Journal of Dentistry 2000; 28: 557-63.

16 Navia JM. Nutrition and dental caries: ten findings to be remembered. International Dental Journal 1996; 46(Suppl. 1): 381-7.

17 Arens U. Oral Health, Diet and Other Factors: Report of the British Nutrition foundation Task Force. Amsterdam: Elsevier, 1998.

18 Arends J, Bosch JJ. In vivo De- and remineralization of dental enamel. Oxford: IRL Press, 1985.

19 Distler W, Bronner H, Hickel R, Petschelt A. Die Saurefreisetzung beim Verzehr von zukerfreien fruchtbonbons in der mundhohle in vivo. Dtsch Zahnaerztliche Zeitschrift 1993; 48(492).

20 Zero D, Lussi A. Etiology of Enamel Erosion-Intrinsic and Extrinsic Factors. London: Martin Dunitz Ltd, 2000.

21 Meurman J, tenCate JM. Pathogenesis and modifying factors of dental erosion. European Journal of Oral Sciences 1996; 104: 199-206.

22 Enwonwu CO. Interface of malnutrition and periodontal diseases. American Journal of Clinical Nutrition 1995; 61(Suppl.): 430S-6S.

23 Enwonwu CO. Cellular and molecular effects of malnutrition and their relevance to periodontal disease. Journal of Clinical Periodontology 1994; 21: 643-57.

24 Enwonwu CO, Meeks VI. Oral candidiasis, HIV, and saliva glucocorticoids. American Journal of Pathology 1996; 148 1313-8.

25 Sidi AD, Ashley PF. Influence of frequent sugar intake on experimental gingivitis. Journal of Periodontology 1984; 55 419-23.

26 Scheinin A, Makinen KK, Ylitalo K. Turku sugar studies V. Final report on the effect of sucrose, fructose and xylitol 
diets on the caries incidence in man. Acta Odontologica Scandinavica 1976; 34: 179-98.

27 Gaengler P, W WP, Sproessig M, Mirgorod M. The effects of carbohydrate reduced diet on development of gingivitis. Clinical Preventive Dentistry 1986; 8: 17-23.

28 Enwonwu CO, Phillips RS, Falkler WA. Nutrition and oral infectious diseases: state of the science. Compendium of Continuing Education in Dentistry 2002; 23: 431-6.

29 WHO/FDI. Global goals for oral health in the year 2000. International Dental Journal 1982; 23: 74-7.

30 Fejerskov $\mathrm{O}$, Baelum V. Changes in Prevalence and Incidence of the Major Oral Diseases. Zurich: Karger, 1998.

31 Holm A-K. Caries in the pre-school child: international trends. Journal of Dentistry 1990; 18: 291-5.

32 Pitts N, Evans DJ. The total dental caries experience of 5year-old children in the United Kingdom. Community Dental Health 1997; 14: 47-52.

33 Frencken JE, Kalsbeck H, Verrips GH. Has the decline in dental caries been halted. International Dental Journal 1990; 40: 225-30.

34 Poulsen S. Dental caries in Danish children and adolescents 1988-1994. Community Dentistry and Oral Epidemiology 1996; 24: $282-5$.

35 Marthaler T, D O'Mullane D, Vrbic V. The prevalence of dental caries in Europe 1990-1995. Caries Research 1996; 30: $237-55$.

36 Leous P, Petersen PE. Oral Health Status and Oral Health Behaviour of Children in Belarus. Copenhagen: World Health Organization Regional Office for Europe, 2000.

37 Szoke J, Petersen PE. Evidence of dental caries decline among children in an East European country (Hungary). Community Dentistry and Oral Epidemiology 2000; 28 : 155-60.

38 Petersen PE, Rusu M. Oral Health Status of Children in Romania, 2000. Copenhagen: World Health Organization Regional Office for Europe; 2001.

39 Kuzmina EM. Oral health status of children and adults in the Russian Federation. Moscow: Ministry of Health and WHO Collaborating Centre for Preventive Oral Care; 1999.

40 Fejerskov O, Baelum V, Ostergaard ES. Root caries in Scandinavia in the 1980s and future trends to be expected in dental caries in adults. Advances in Dental Research 1993; 7: 4-14.

41 Holst D, Schuller AA. Oral health changes in a adult Norwegian population-a cohort analytical study. Community Dentistry and Oral Epidemiology 2000; 28: 102-11.

42 O'Mullane D, Whelton H. Oral Health of Irish Adults 19891990. Dublin: Stationery Office, $1992 \mathrm{vol} 1989$.

43 O'Mullane D., Oral Health Systems in European Union Countries-Biomed Project. Cork: University College Cork, Ireland, 1996.

44 Services USDoHaH. Oral Health in America: A report of the Surgeon General. Rockville, MD: Department of Health and Human Services, National Institute of Dental and CranioFacial Research, National Institute of Health, 2002.

45 Petersen PE. Oral health behaviour of 6-year old Danish children. Acta Odontologica Scandinavica 1992; 50: 57-64.

46 Jarvinen VK, Rytomaa I, Heinonen OP. Risk factors in dental erosion. Journal of Dental Research 1991; 70: 942-7.

47 Millward A, Shaw L, Smith AJ, Rippin JW, Harrington E. The distribution and severity of tooth wear and the relationship between erosion and dietary constituents in a group of children. International Journal of Paediatric Dentistry 1994; 4: 152-7.

48 Shaw L, Smith AJ. Dental erosion-the problem and some practical solutions. British Dental Journal 1999; 186: $115-8$.

49 ten Cate JM, Imfeld T. Dental erosion, summary. European Journal of Oral Sciences 1996; 104: 241-4.
50 Hinds K, Gregory J. National Diet and Nutrition Survey: Children Aged 1.5-4.5 Years. Volume 2: Report of the Dental Survey. London: HM Stationery Office, 1995.

51 O'Brien M. Children's Dental Health in the United Kingdom. London: H M Stationery Office, 1994.

52 Walker A, Gregory J, Bradnock G, Nunn J, White D. National Diet and Nutrition Survey: young people aged 4 to 18 Years. Volume 2: Report of the Oral Health Survey. London: The Stationery Office; 2000.

53 Sreebny LM. Sugar availability, sugar consumption and dental caries. Community Dentistry and Oral Epidemiology 1982; 10: 1-7.

54 Marthaler T. Changes in the prevalence of dental caries: how much can be attributed to changes in diet? Caries Research 1990; 24: 3-15.

55 Woodward M, Walker ARP. Sugar and dental caries: The evidence from 90 countries. British Dental Journal 1994; 176: $297-302$.

56 Nadanovsky P. Letter. British Dental Journal 1994; 177(8): 280.

57 Ruxton CHS, Garceau FJS, Cottrell RC. Guidelines for sugar consumption in Europe. Is a qualitative approach justified? European Journal of Clinical Nutrition 1999: 53 503-13.

58 Sognnaes RF. Analysis of wartime reduction of dental caries in European children. American Journal of Diseases of Childhood 1948; 75: 792-821.

59 Takeuchi M. Epidemiological study on Japanese children before, during and after World War II. International Dental Journal 1961; 11: 443-57.

60 Marthaler TM. Epidemiological and clinical dental findings in relation to intake of carbohydrates. Caries Research 1967; 1: $222-38$.

61 Weaver R. Fluorine and war-time diet. British Dental Journal 1950; 88: 231-9.

62 Miyazaki H, Morimoto M. Changes in caries prevalence in Japan. European Journal of Oral Sciences 1996; 104: 452-8.

63 Bang G, Kristoffersen T. Dental caries and diet in an Alaskan Eskimo population. Scandinavian Journal of Dental Research 1972; 80: 440-4.

64 Emslie DR. A dental health survey in the Republic of Sudan. British Dental Journal 1966; 120: 167-78.

65 Olsson B. Dental health situation in privileged children in Addis Ababa Ethiopia. Community Dentistry and Oral Epidemiology 1979; 7: 37-41.

66 MacGregor AB. Increasing caries incidence and changing diet in Ghana. International Dental Journal 1963; 13: 516-22.

67 Sheiham A. The prevalence of dental caries in Nigerian populations. British Dental Journal 1967; 123: 144-8.

68 Fisher FJ. A field study of dental caries, periodontal disease and enamel defects in Tristan da Cunha. British Dental Journal 1968; 125: 447-53.

69 Roberts IF, Roberts GJ. Relation between medicines sweetened with sucrose and dental disease. British Medical Journal 1979; 2: 14-16.

70 Anaise JZ. Prevalence of dental caries among workers in the sweets industry in Israel. Community Dentistry and Oral Epidemiology 1978; 8: 142-5.

71 Katayama T, Nagagawa N, Honda O, Tani H, Okado S, Suzuki S. Incidence and distribution of Strep mutans in plaque from confectionery workers. Journal of Dental Research 1979; 58(Special issue): 2251.

72 Petersen PE. Dental health among workers at a Danish chocolate factory. Community Dentistry and Oral Epidemiology 1983; 11: 337-41.

73 Masalin K, Murtamaa H, Meurman JH. Oral health of workers in the modern Finnish confectionery industry. Community Dentistry and Oral Epidemiology 1990; 18: 126-30.

74 Bradford EW, Crabb HSM. Carbohydrates and the 
incidence of caries in the deciduous dentition. London: Pergamon Press, 1963.

75 Harris R. Biology of the children of Hopewood House, Bowral, Australia, 4. Observations on dental caries experience extending over 5 years (1957-61). Journal of Dental Research 1963; 42: 1387-99.

76 Silverstein SJ, Knapp JF, Kircos L, Edwards H. Dental caries prevalence in children with a diet free of refined sugar. American Journal of Public Health 1983; 73: 1196-9.

77 Newbrun E, Hoover C, Mettraux G, Graf H. Comparison of dietary habits and dental health of subjects with hereditary fructose intolerance and control subjects. Journal of the American Dental Association 1980; 101: 619-26.

78 Gustafsson BE, Quensel CE, Lanke LS, Lundquiat C, Grahnen H, Bonow BE, et al. The Vipeholm dental caries study. The effect of different levels of carbohydrate intake on caries activity in 436 individuals observed for 5 years. Acta Odontologica Scandinavica 1954; 11: 232-364.

79 Rugg-Gunn AJ. Nutrition and Dental Health. Oxford: Oxford Medical Publications, 1993.

80 Granath L-E, Rootzen H, Liljegren E, Holst K, Kohler L. Variation in caries prevalence related to combinations of dietary and oral hygiene habits and chewing fluoride tablets in 4-year old children. Caries Research 1978; 12: 83-92.

81 Hausen H, Heinomen OP, Paunio I. Modification of occurrence of caries by children by toothbrushing and sugar exposure in fluoridated and non-fluoridated area. Community Dentistry and Oral Epidemiology 1981; 9: $103-7$.

82 Kleemola-Kujala E, Rasanen L. Relationship of oral hygiene and sugar consumption to risk of caries in children. Community Dentistry and Oral Epidemiology 1982; 10 $224-33$.

83 Schroder U, Granath L. Predictive value of dietary habits and oral hygiene for the occurrence of caries in 3-year-olds. Community Dentistry and Oral Epidemiology 1983; 11: $308-11$.

84 Stecksen-Blicks C, Arvidsson S, Holm A-K. Dental health, dental care and dietary habits in children in different parts of Sweden. Acta Odontologica Scandinavica 1985; 43: 59-67.

85 Garn SM, Cole PE, Solomon MA, Schaefer AE. Relationships between sugar-foods and DMFT in 1968-1970. Ecology of Food and Nutrition 1980; 9: 135-8.

86 Marques APF, Messer LB. Nutrient intake and dental caries in the primary dentition. Pediatric Dentistry 1992; 14: $314-21$.

87 Persson L-A, Holm A-K, Arvidsson S, Samuelson G. Infant feeding and dental caries, a longitudinal study of Swedish children. Swedish Dental Journal 1985; 9: 201-6.

88 Stecksen-Blicks C, Holm A-K. Dental caries, tooth trauna, malocclusion, fluoride usage, toothbrushing and dietary habits in 4-year-old Swedish children: changes between 1967 and 1992. International Journal of Paediatric Dentistry 1995; 5: 143-8.

89 Al-Tamimi S, Petersen PE. Oral health situation of schoolchildren, mothers and schoolteachers in Saudi Arabia. International Dental Journal 1998; 48: 180-6.

90 Peng B, Petersen PE, Fan MW, Tai BJ. Oral health status and oral health behaviour of 12-year-old urban schoolchildren in PR China. Community Dental Health 1997; 14: 238-44.

91 Sundin B, Granath L, Birkhed D. Variation of posterior approximal caries incidence with consumption of sweets with regard to other caries-related factors in 15-18-yearolds. Community Dentistry and Oral Epidemiology 1992; 20: $76-80$.

92 Lachapelle-Harvey D, Sevigny J. Multiple regression analysis of dental status and related food behaviour of French Canadian adolescents. Community Dentistry and Oral Epidemiology 1985; 13: 226-9.
93 Grindefjord M, Dahllof G, Nilsson B, Modeer T. Stepwise prediction of dental caries in children up to 3.5 years of age. Caries Research 1996; 30: 256-66.

94 Stecksen-Blicks C, Gustafsson L. Impact of oral hygiene and use of fluorides on caries increment in children during one year. Community Dentistry and Oral Epidemiology 1996; 14: $185-9$

95 Rugg-Gunn AJ, Hackett AF, Appleton DR, Jenkins GN, Eastoe JE. Relationship between dietary habits and caries increment assessed over two years in 405 English adolescent schoolchildren. Archives of Oral Biology 1984; 29: 983-92.

96 Burt BA, Eklund SA, Morgan KJ, Larkin FE, Guire KE, Brown LO, et al. The effects of sugars intake and frequency of ingestion on dental caries increment in a 3-year longitudinal study. Journal of Dental Research 1988; 67: 1422-9.

97 Burt B, Szpunar SM. The Michigan Study: relationship between sugars intake and dental caries over 3 years. International Dental Journal 1994; 44: 230-40.

98 Rose G. The Strategy of Preventive Medicine. Oxford: Oxford University Press, 1993.

99 Konig KP, Schmid P, Schmid R. An apparatus for frequencycontrolled feeding of small rodents and its use in dental caries experiments. Archives of Oral Biology 1968; 13: $13-26$.

100 Firestone AR, Imfeld T, Muhlemann HR. Effect of the length and number of intervals between meals on caries in rats. Caries Research 1984; 18: 128-33.

101 Karlsbeek H, Verrips GH. Consumption of sweet snacks and caries experience of primary school children. Caries Research 1994; 28: 477-83.

102 Holbrook WP, Arnadottir IB, Takazoe I, Birkhed D, Frostell G. Longitudinal study of caries, cariogenic bacteria and diet in children just before and after starting school. European Journal of Oral Sciences 1995; 103: 42-5.

103 Holbrook WP, Kristinsson MJ, Gunnarsdottir S, Briem B. Caries prevalence, Streptococcus mutans and sugar intake among 4-year-old urban children in Iceland. Community Dentistry and Oral Epidemiology 1989; 17: 292-5.

104 Holt RD, Joels D, Winter GB. Caries in preschool children; the Camden study. British Dental Journal 1982; 153: 107-9.

105 Hankin JH, Chung CS, Kau MCw. Genetic and epidemiological studies of oral characteristics in Hawaii's school children: dietary patterns and caries prevalence. Journal of Dental Research 1973; 52: 1079-86.

106 Bjarnason S, Finnbogason SY, Noren JG. Sugar consumption and caries experience in 12- and 13-year-old Icelandic children. Acta Odontologica Scandinavica 1989; 47: 315-21.

107 Bagramian RA, Russell AL. Epidemiological study of dental caries experience and between-meal patterns. Journal of Dental Research 1973; 52: 342-7.

108 Bergendal B, Hamp SE. Dietary pattern and dental caries in 19-year-old adolescents subjected to preventive measures focused on oral hygiene and/or fluorides. Swedish Dental Journal 1985; 9: 1-7.

109 Larsson B, Johansson I, Ericson T. Prevalence of caries in adolescents in relation to diet. Community Dentistry and Oral Epidemiology 1992; 20: 133-7.

110 Mikx FHM, Hoevel JSvd, Plasschaert AJM, Konig KG. Effect of Actinomyces viscosus on the establishment and symbiosis of Streptococcus mutans and Streptococcus sanguis on SPF rats on different sucrose diets. Caries Research 1975; 9: 1-20.

111 Guggenheim B, Konig KG, Herzog E, Muhlemann HR. The cariogenicity of different dietary carbohydrates tested on rats in relative gnotobiosis with a streptococcus producing extracellular polysaccharide. Helvetica Odontologica Acta 1966; 10: 101-13. 
112 Hefti A, Schmid R. Effect on caries incidence in rats of increasing dietary sucrose levels. Caries Research 1979; 13: 298-300.

113 Szpunar SM, Eklund SA, Burt BA. Sugar consumption and caries risk in schoolchildren with low caries experience. Community Dentistry and Oral Epidemiology 1995; 23: 142-6.

114 Jamel HA, Sheiham A, Watt RG, Cowell CR. Sweet preference, consumption of sweet tea and dental caries: studies in urban and rural Iraqi populations. International Dental Journal 1996; 47: 213-7.

115 Cleaton-Jones P, Richardson BD, Winter GB, Sinwell R, Rantsho HM, Jodaikin A. Dental caries and sucrose intake in five South African pre-school groups. Community Dentistry and Oral Epidemiology 1984; 12: 381-5.

116 Rodriguez CS, Watt RG, Sheiham A. The effects of dietary guidelines on sugar intake and dental caries in 3-year-olds attending nurseries. Health Promotion International 1999; 14: 329-35.

117 Ismail AI, Burt BA, Eklund SA. The cariogenicity of soft drinks in the United States. Journal of the American Dental Association 1984; 109: 241-5.

118 Jenkins GN, Ferguson DB. Milk and dental caries. British Dental Journal 1966; 120: 472-7.

119 Frostell G, Birkhed D, Edwardsson S, Goldberg P, Petersson L-P, Priwe C, et al. Effect of partial substitution of invert sugar from sucrose in combination with duraphat treatment on caries development in pre-school children: the Malmo Study. Caries Research 1991; 25: 304-10.

120 Murray JJ. Appropriate Use of Fluorides for Human Health. Geneva: World Health Organization, 1986.

121 Beighton D, Adamson A, Rugg-Gunn A. Associations between dietary intake, dental caries experience and salivary bacterial levels in 12-year-old English schoolchildren. Archives of Oral Biology 1996; 41: 271-80.

122 Holt RD. Foods and drinks at four daily time intervals in a group of young children. British Dental Journal 1991; 170: $137-43$.

123 Kunzel W, Fischer T. Rise and fall of caries prevalence in German towns with different F concentrations in drinking water. Caries Research 1997; 31: 166-73.

124 Burt B, Pai S. Sugar consumption and caries risk: a systematic review. Journal of Dental Education 2001; 65(10): 1017-23.

125 Edgar WM. Prediction of the cariogenicity of various foods. International Dental Journal 1985; 35: 190-4.

126 Brudevold F, Goulet D, Terani A, Attarzadeh F, Houte Jv. Intraoral demineralisation and maltose clearance from wheat starch. Caries Research 1985; 19: 136-44.

127 Koulourides T, Bodden R, Keller S, Manson-Hing L, Lastra J, Housch T. Cariogenicity of nine sugars tested with an intraoral device in man. Caries Research 1976; 101: 427-41.

128 Grenby TH. The effects of some carbohydrates on experimental dental caries in the rat. Archives of Oral Biology 1963; 8: 27-30.

129 Grenby TH. The effects of starch and sugar diets on dental caries. British Dental Journal 1970; 128: 575-8.

130 Bowen WH, Amsbaugh SM, Monnell-Torens S, Brunelle S, Kuzmiak-Jones J, Cole MF. A method to assess cariogenic potential of foodstuffs. Journal of the American Dental Association 1980; 100: 677-81.

131 Firestone AR, Schmid R, Muhlemann HR. Cariogenic effects of cooked wheat starch alone or with sucrose and frequency-controlled feeding in rats. Archives of Oral Biology 1982; 27: 759-63.

132 Mundorff SA, Featherstone JDB, Eisenberg AD, Cowes E, Curzon MJE. Cariogenicpotential of foods. II. Relationship of food composition, plaque microbial counts and salivary parameters to caries in the rat model. Caries Research 1994; 28: $106-15$.

133 Toverud $G$. The influence of war and post war condition on the teeth of Norwegian school children II and III. Milbank Memorial Fund Quarterly 1957; 35: 127-96.

134 Russell AL, Littleton NW, Leatherwood EC, Syndow GE, Green JC. Dental surveys in relation to nutrition. Public Health Reports 1960; 75: 717-23.

135 Alfonsky D. Some observations on dental caries in central China. Journal of Dental Research 1951; 30: 53-61.

136 Sreebny LM. Cereal availability and dental caries. Community Dentistry and Oral Epidemiology 1983; 11: 148-55.

137 Magrill DS. The reduction of the solubility of hydroxyapatite in acid by adsorption of phytate from solution. Archives of Oral Biology 1973; 18: 591-600.

138 Nizel AE, Harris RS. The effects of phosphates on experimental dental caries: a literature review. British Dental Journal 1964; 43: 1123-36.

139 Ludwig TG, Bibby BG. Acid production from different carbohydrate foods in plaque and saliva. Journal of Dental Research 1957; 36: 56-60.

140 Hussein I, Pollard MA, Curzon MEJ. A comparison of the effects of some extrinsic and intrinsic sugars on dental plaque pH. International Journal of Paediatric Dentistry 1996; 6: 81-6.

141 Imfeld TN. Identification of low caries risk dietary components. Monographs in Oral Science 1983; 11: 1-198.

142 Imfeld TN, Schmid R, Lutz F, Guggenheim B. Cariogenicity of Milchschmitte (Ferrero-GmbH) and apple in programmefed rats. Caries Research 1991; 25: 352-8.

143 Stephan RM. Effects of different types of foods on dental health in experimental animals. Journal of Dental Research 1966; 45: 1551-61.

144 Savara BS, Suher T. Dental caries in children one to six years of ages as related to socio-economic level, food habits and toothbrushing. Journal of Dental Research 1955; 34: $870-5$.

145 Kleemola-Kujala E, Rasanen L. Dietary pattern of Finnish children with low and high caries experience. Community Dentistry and Oral Epidemiology 1979; 7: 199-205.

146 Martinsson T. Socio-economic investigation of school children with high and low caries frequency. Odontological Review 1972; 23: 93-114.

147 Clancy KL, Bibby BG, Goldberg HJV, Ripa LW, Barenie J. Snack food intake of adolescents and caries development. Journal of Dental Research 1977; 56: 568-73.

148 Grobler SR, Blignaut JB. The effect of a high consumption of apples or grapes on dental caries and periodontal disease in humans. Clinical Preventive Dentistry 1989; 11: $8-12$.

149 Grenby TH. The effect of glucose syrup on dental caries in the rat. Caries Research 1972; 6: 52.

150 Moynihan PJ, Gould MEL, Huntley N, Thorman S. Effect of glucose polymers in water, milk and a milk substitute on plaque $\mathrm{pH}$ in vitro. International Journal of Paediatric Dentistry 1996; 6: 19-24.

151 Grenby TH, Mistry HM. Properties of maltodextrins and glucose syrups in experiments in vitro and in the diets of laboratory animals relating to dental health. British Journal of Nutrition 2000; 84: 565-74.

152 Roberts PG, Hayes ML. Effects of 20-deoxy-D-glucose and other sugar analogues on acid production from sugars by human dental plaque bacteria. Scandinavian Journal of Dental Research 1980; 88: 201-9.

153 Ooshima T, Fujiwarra T, Taki T, Izumintani A, Sobue S, Hamada S. The caries inhibitory effects of GOS-sugar in vitro and in rat experiments. Microbiology and Immunology 1998; 32: 1093-105.

154 Koga T, Horikoshi T, Fujiwarra T, Hamada S. Effects of pannose on glucan synthesis and cellular adherence by 
Streptococcus mutans. Microbiology and Immunology 1988; 32: 25-31.

155 Hartmink R, Quataert MCJ, Leare KMJV, Nout MJR, Rombouts FM. Degradation and fermentation of fructooligosaccharides by oral streptococci. Journal of Applied Bacteriology 1995; 79: 551-7.

156 Moynihan PJ, McIlmoyle S, Rowshanaei R, Moxon R, Russell RRB. Acidogenic potential of fructooligosaccharides: incubation studies and plaque $\mathrm{pH}$ studies. Caries Research 2001; 35: 275.

157 Rugg-Gunn AJ, Edgar WM, Geddes DAM, Jenkins GN. The effect of different meal patterns upon plaque $\mathrm{pH}$ in human subjects. British Dental Journal 1975; 139: 351-6.

158 Gedalia I, Ben-Mosheh S, Biton J, Kogan D. Dental caries protection with hard cheese consumption. American Journal of Dentistry 1994; 7: 331-2.

159 Frostell G. Effects of milk, fruit juices and sweetened beverages on the $\mathrm{pH}$ of dental plaques. Acta Odontologica Scandinavica 1970; 28: 609-22.

160 Rugg-Gunn AJ, Roberts GJ, Wright WG. The effect of human milk on plaque in situ and enamel dissolution in vitro compared with bovine milk, lactose and sucrose. Caries Research 1985; 19: 327-34

161 Reynolds EC, Johnson IH. Effect of milk on caries incidence and bacterial composition of dental plaque in the rat. Archives of Oral Biology 1981; 26: 445-51.

162 Bowen WH, Pearson SK, Wuyckhuyse BC, Tabak LA Influence of milk, lactose-reduced milk, and lactose on caries in desalivated rats. Caries Research 1991; 25: 283-6.

163 Silver DH. A longitudinal study of infant feeding practice, diet and caries related to social class in children aged 3 and 8-10 years. British Dental Journal 1987; 163: 296-300.

164 Craig GC. The use of a calcium sucrose phosphates-calcium orthophosphate complex as a cariostatic agent. British Dental Journal 1975; 138: 25-8

165 Linke HAB, Salgado T, Retino M, Legeros RZ. Effect of black tea on caries formation in hamsters. Journal of Dental Research 2000; 79: 594

166 Lingstrom P, Wu CD, Wefel JS. In vivo effects of black tea infusion on dental plaque. Journal of Dental Research 2000; 79: 594.

167 Gibney M. Consumption of sugars. Workshop on the evaluation of the nutritional and health aspects of sugars. American Journal of Clinical Nutrition 1995; 62(Suppl.): 178S-94S.

168 Fletcher E, Adamson A, Rugg-Gunn A. Twenty years of change in the dietary intake and BMI of Northumbrian adolescents. Proceedings of the Nutrition Society 2001; 80 210A.

169 Alexy U, Sichert-Hellert W, Kersting M. Fifteen year time trends in energy and macronutrient intake in German children and adolescents: results of the DONALD study. British Journal of Nutrition 2002; 87: 595-604.

170 Cole-Hamilton I, Gunner K, Loeverkus C, Starr J. A study among dietitians and adult members of their households of the practicalities and implications of following proposed dietary guidelines in the UK. Human Nutrition Applied Nutrition 1986; 40A: 365-89.

171 Thomas AK. Further observations on the influence of citrus fruit juices on human teeth. New York State Dental Journal 1957; 23: 424-30.

172 Stabholz A, Raisten J, Markitziu A. Tooth enamel dissolution from erosion or etching and subsequent caries development. Journal of Periodontology 1983; 7: 100-8.

173 Linkosalo E, Markkanen H. Dental erosions in relation to lactovegetarian diet. Scandinavian Journal of Dental Research 1985; 93: 436-41.

174 Millward A, Shaw L, Smith AJ. Dental erosion in 4 year old children from differing socio-economic backgrounds. Journal of Dentistry for Children 1994; 61: 263-6.
175 Gedalia I, Dakuar A, Shapiro H, Leminstein I, Goultschin J, Rahamin E. Enamel softening with coca-cola and rehardening with milk or saliva. American Dental Journal 1991: 4: 120-2.

176 Gedalia I, Lonat-Bendat D, Ben-Moshek S, Shapiro H. Tooth enamel softening with a cola type drink and rehardening with hard cheese or stimulated saliva in situ. Journal of Oral Rehabilitation 1991; 18: 501-6.

177 Holloway PJ, Mellanby M, Stewart RJC. Fruit drinks and tooth erosion. British Dental Journal 1958; 104: 305-9.

178 Miller CD. Erosion of molar teeth by acid beverages. Journal of Nutrition 1950; 41: 63-71.

179 Fuller JL, Johnson WW. Citric acid consumption and the human dentition. Journal of the American Dental Association 1977; 95: 80-8.

180 High AS. An unusual pattern of dental erosion. British Dental Journal 1977; 143: 403-4.

181 Guggenheimer J, Schneider LG. Tooth erosion associated with excessive use of an artificially sweetened cola beverage. Journal of Preventive Dentistry 1980; 6: 261-2.

182 Smith AJ, Shaw L. Baby fruit juice and tooth erosion. British Dental Journal 1987; 162: 65-7.

183 Giunta JL. Dental erosion resulting from chewable vitamin C tablet. Journal of the American Dental Association 1983 107: 253-6.

184 Grenby TH, Mistry HM, Desai T. Potential dental effects of infants' fruit drinks studied in vitro. British Journal of Nutrition 1990; 64: 273-83.

185 Meurman J, Rytomaan I, Kari K, Laakso T, Murtomaa H Salivary $\mathrm{pH}$ and glucose after consuming various beverages including sugar-containing drinks. Caries Research 1987; 21: $353-9$.

186 Rugg-Gunn AJ, Nunn JH. Nutrition, Diet and Oral Health Oxford: Oxford Medical Publications, 1999.

187 Newbrun E. Sucrose in the dynamics of the carious profess International Dental Journal 1982; 32: 13-23.

188 Sheiham A. Sugars and dental caries. Lancet 1983; 1: 282-4.

189 Sheiham A. Why sugars consumption should be below $15 \mathrm{~kg}$ per person per year in industrialised countries; the dental evidence. British Dental Journal 1991; 171: 63-5.

190 WHO. Diet, Nutrition and the Prevention of Chronic Diseases. Technical Report Series No 797. Geneva: World Health Organization, 1990.

191 Freire MDCM, Cannon G, Sheiham A. Sugar and Health in One Hundred and Fifteen Authoritative Scientific Reports on Food Nutrition and Public Health Published Throughout the World in Thirty Years Between 1961 and 1991. Department Monograph Series No 1. London: University College London, 1961.

192 Bellini H, Arneberg P, Fehr Fvd. Oral hygiene and caries. A review. Acta Odontologica Scandinavica 1981; 39: 257-65.

193 Authority HE. The Scientific Basis of Dental Health Education. A Policy Document, 4th Ed. London: Health Education Authority, 1996.

194 Sutcliff P. Oral cleanliness and dental caries. Oxford: Oxford University Press, 1996.

195 Takahashi K. Statistical study on caries incidence in the first molar in relation to the amount of sugar consumption Bulletin of the Tokyo Dental College 1961; 2: 44-57.

196 Takeuchi M. On the epidemiological principles in dental caries attack. Bulletin of the Tokyo Dental College 1962; 3 96-111.

197 Knowles EM. The effects of enemy occupation on the dental condition of children in the Channel Islands. Monthly Bulletin of the Ministry of Health 1946 (August) $161-72$.

198 Schulerud A. Dental Caries and Nutrition During Wartime in Norway. Oslo: Fabritius and Sonners Trykkeri, 1950.

199 Buttner. Zuckeraufnahme und Karies [Sugar and Caries]. Basel: Karger, 1971. 